\title{
SHEAR RESISTANCE OF SFRSCC SHORT-SPAN BEAMS WITHOUT TRANSVERSAL REINFORCEMENTS
}

Fatemeh Soltanzadeh*, Ali Edalat Behbahani, Hadi Mazaheripour, Joaquim A.O. Barros ISISE, Dep. Civil Eng., School Eng., University of Minho, Campus de Azurém 4800-058 Guimarães, Portugal

\begin{abstract}
Corrosion of steel reinforcements, especially stirrups, is considered as one of the most common reasons that shorten the service life of the reinforced concrete structures. This study aims to replace the stirrups of the beams by means of a tailor made steel fiber reinforced self-compacting concrete (SFRSCC). A hybrid flexural reinforcement system was used for all these beams, composed of glass fiber reinforced polymer (GFRP) rebars placed near to the outer surface of the tensile zone and steel reinforcements positioned with higher SFRSCC cover to be protected against the corrosion, which is considered another strategy for enhancing the durability and attending fire issues in terms of safety at ultimate limit states. The effectiveness of varying the prestressing force applied to GFRP bars to improve the shear capacity and failure mode of the designed elements is evaluated. By considering the obtained experimental results, the predictive performance of some analytical formulations for the shear resistance of fiber reinforced concrete beams was assessed. All formulations demonstrate acceptable accuracy for design purposes, but the one proposed by CEB-FIP Model Code 2010 predicts more conservative shear resistance.
\end{abstract}

KEYWORDS: shear resistance; short-span beams; fiber reinforced self-compacting concrete; prestress; FEM analysis.

*Author to whom the correspondence should be sent (soltanzadehfaranak@gmail.com). 


\section{INTRODUCTION}

Nowadays there is a big demand for enhancing the sustainability and durability of concrete constructions. All the efforts that can be done for improving the durability of these structures have significant impact in terms of their sustainability due to the relatively high costs of rehabilitation. The corrosion of steel stirrups is one of the common causes that limits the long-term performance of reinforced concrete (RC) structures. The high cost for rehabilitating such corroded RC elements frequently motivates the building's demolishment, which brings economic, social and environmental adverse impacts. On the other hand, the activities for producing and placing conventional shear reinforcement are very labor-intensive, and increase the production time and cost of the elements. Finding a material system that does not need conventional shear reinforcement is a relatively recent challenge for the scientific community [1-3]. The attainment of this objective is not only a step forward to avoid corrosion problems in concrete structures, but also to reduce the element thickness and the structural self-weight, leading to a better production efficiency [4]. In accordance with the literature, steel fibers can be considered as a shear reinforcement that significantly affects the ultimate shear capacity and ductility of structural elements, and may replace partially or totally the conventional shear reinforcements, depending on the concrete strength class, as well as the type and dosage of steel fibers [5,6].

The corrosion of steel flexural reinforcements is another responsible for the deterioration and damage of RC members. The use of non-corrodible fiber reinforced polymer (FRP) bars as a flexural reinforcement, as near to the tensile surface as possible, can be a solution for enhancing the durability and sustainability of concrete elements. Glass fiber reinforced polymer (GFRP) bars are being employed as a promising alternative for replacing steel flexural reinforcement [7-9]. The major driving force behind this effort is the superior performance of this type of reinforcement in corrosive environments, non-conductivity, and high strength-to-weight ratio [10, 11]. Despite of all these advantages, the GFRP has a relatively low modulus of elasticity and brittle tensile failure. Additionally, the bond performance between FRP bars and concrete is normally lower than conventional steel bars, and strongly depends on the surface treatments of the bar [12-14]. To improve the ductility and accomplish the serviceability limit state requirements of the GFRP reinforced concrete beams, application of steel bars as an additional reinforcement is suggested, resulting a hybrid reinforcing system [15]. This system offers lower cost constructions than when exclusively FRP reinforcements are used, and also higher ductile behavior and longer service life compared to that of applying solely steel reinforcements [9]. 
Considering all the proposed techniques for enhancing the durability of concrete structures, a new design framework for producing highly durable and structurally effective prefabricated concrete beams is introduced in the present study. These elements are produced by means of developing a steel fiber reinforced self-compacting concrete (SFRSCC) of shear resistance capable of suppress the steel stirrups without occurring shear failure when suitable level of prestress is also applied to the flexural reinforcement. The optimum dosage of steel fibers reduces the brittleness of concrete and enhances the bond behavior between concrete and the reinforcing system [16]. The beams were flexurally reinforced with a hybrid system composed of GFRP and steel longitudinal reinforcements. To achieve a low probability of corrosion occurrence for steel bars, the system of reinforcements is properly disposed in order to assure a relatively thick SFRSCC cover for the steel reinforcement. The GFRP bars are placed with the minimum cover thickness in order to provide a higher internal arm and, consequently, mobilizing their relatively high tensile strength [17]. In addition to all the adopted arrangements for improving the ductility, such as using a SFRSCC of high strength and high post-cracking resistance, as well as the application of the hybrid GFRP-steel flexural reinforcements, the GFRP bars are prestressed to obviate the deficiencies created by their low modulus of elasticity. In fact, the structural performances of the developed elements, especially the shear capacity and ductility, are enhanced by applying the hybrid reinforcements with a certain prestress level [18]. A numerical strategy is accompanied to analyze the applicability of the developed system for increasing the shear capacity of the short-span beams.

The brittleness of the beams without shear reinforcements is also dependent on the shear span, $a$, to effective depth, $d$, ratio, $a / d$, of the elements, due to the arch effect that starts being pronounced when $a / d \leq 2.5$. Accordingly, the short-span beams with $1<a / d \leq 2.5$ behave significantly different from slender, $a / d>2.5$, and deep, $a / d \leq 1$, beams [19] under the shear loading configuration. Although the considerable experimental and theoretical investigations already carried out on the shear behavior of fiber reinforced concrete (FRC) beams, the available empirical and semi empirical formulations have been calibrated mainly based on the results obtained by testing slender beams with $a / d>2.5$ [20]. On the other hand, due to the specificities introduced by using steel fibers, the accurate evaluation of the shear capacity of steel fiber reinforced concrete (SFRC) beams is still a challenge. Hence, most of the guidelines do not support the total replacement of stirrups by steel fibers (ACI 544.1R-96 [21], Eurocode 2 [22]), unless strain hardening cement composites are used (CEB-FIP Model Code 2010 [23]; the abbreviator MC2010 will be adopted). Even some guidelines do not have a design framework to simulate the contribution of steel fibers for the shear capacity of FRC structures (ACI 318-11 [24]). Some guidelines, such as MC2010 [23] and RILEM TC-162-TDF [25], have already considered the influence of fiber 
contribution for predicting the shear resistance of SFRC elements. In addition to these guidelines, some alternative formulas are proposed by researchers, taking into account the effect of steel fibers (Soetens [1], Khuntia et al. [26], Imam et al. [27], Ashour et al. [28], and Narayanan and Darwish [30]). In the present research, the predictive performance of MC2010 [23], and RILEM TC-162-TDF [25] guidelines, and the formula proposed by Soetens [1], is assessed by considering the results obtained in the experimental program carried out, as well as those results available in the literature.

\section{DESIGN METHOD}

\subsection{Introduction}

The present section introduces the applied method for determining the appropriate shear span and fiber dosage of the beams for the experimental program to be carried out in the scope of this research project. For this purpose it was considered the influence of these factors on the relative flexural capacity (i.e. the dimensionless ratio of the ultimate moment to the flexural moment, $M_{u} / M_{f l}$ ) and, consequently the shear resistance of these elements. Accordingly, an optimum dosage of steel fiber was designed and applied to increase the ultimate strength of the short-span beam without stirrups and to attain as close as possible its full flexural capacity $\left(M_{u} / M_{f l} \approx 1\right)$ regardless to the type of the elements.

\subsection{Relative flexural capacity and failure mode}

According to the formula proposed by Imam et al. [30], the nominal flexural moment, $M_{f l}$, of high strength fiber reinforced concrete beams without stirrups can be calculated as:

$$
M_{f l}=\frac{1}{2} \rho_{s} f_{s y} b d^{2}(2-\Gamma)+0.83 F_{f} b d^{2}(0.75-\Gamma)(2.15+\Gamma)
$$

where the parameter " $\Gamma$ " is obtained from:

$$
\Gamma=\frac{\rho_{s} f_{s y}+2.32 F_{f}}{0.85 f_{c m}+3.08 F_{f}}
$$


in which $F_{f}=\left(l_{f} / d_{f}\right) V_{f} \cdot \eta_{f}$ is the fiber factor, $\rho_{s}=A_{s} / b . d$ is the steel flexural reinforcement ratio, $l_{f}$ and $d_{f}$ are respectively the length and diameter of the steel fibers, $V_{f}$ is fiber volume fraction, $\eta_{f}$ is the bond efficiency factor, which is assumed to be unity for the hooked ends steel fibers, $b$ and $d$ are respectively width and effective depth of beams, $f_{c m}$ is compressive strength of concrete, $f_{s y}$ is yield strength and $A_{s}$ is the cross sectional area of the tension steel reinforcement.

Eq. (1) can be adapted to estimate the flexural capacity of the SFRSCC beams flexurally reinforced with the adopted hybrid system of GFRP and steel bars by introducing “ $\rho_{\text {seq,GFRP }} . f_{\text {GFRP }}$ " corresponding to the GFRP reinforcement in the $1^{\text {st }}$ term of Eqs. (1) and (2), where “ $\rho_{\text {seq,GFRP }}=A_{\text {GFRP }} \cdot E_{\text {GFRP }} /\left(b \cdot d_{\text {GFRP }} E_{s}\right)$ " is the GFRP reinforcement ratio converted into an equivalent steel reinforcement ratio, " $A_{G F R P}$ " is its cross sectional area, “ $E_{\text {GFRP }}$ " is its modulus of elasticity, and " $d_{\text {GFRP }}$ " is the distance of the centroid of the GFRP bars to the top face of the section, respectively. $E_{s}$ is the modulus of elasticity of steel reinforcements. Hence, the nominal flexural strength of the beams can be predicted by:

$$
M_{f l}=\frac{1}{2}\left(\rho_{s e q, G F R P} f_{G F R P}+\rho_{s} f_{s y}\right) b d_{s, e q}^{2}\left(2-\Gamma_{e q}\right)+0.83 F_{f} b d_{s, e q}^{2}\left(0.75-\Gamma_{e q}\right)\left(2.15+\Gamma_{e q}\right)
$$

This formula can be simply obtained based on the force equilibrium, strain compatibility and the rectangular stress block hypothesis [23] for the stress distribution in compressive concrete and the stress in tensile GFRP and steel reinforcements as well as the contribution of steel fibers in the tensile zone in the ultimate limit state as presented in Fig. 1. In Eq.(3) the $f_{\text {GFRP }}$ is the tensile strength in the GFRP bars, calculated according to the equation proposed by ACI440.IR-06 [31]:

$$
f_{\text {GFRP }}=\sqrt{\frac{1}{4}\left(\frac{A_{s} f_{s y}}{A_{G F R P}}+E_{G F R P} \varepsilon_{c u}\right)^{2}+\left(0.85 \frac{\beta_{1} f_{c m}}{\rho_{s e q, G F R P}}-\frac{A_{s} f_{s y}}{A_{\text {GFRP }}}\right) E_{G F R P} \varepsilon_{c u}}-\frac{1}{2}\left(\frac{A_{s} f_{s y}}{A_{G F R P}}+E_{G F R P} \varepsilon_{c u}\right) \leq f_{\text {GFRP }, u}
$$

and $d_{s, e q}$ is the equivalent steel effective depth:

$$
d_{s, e q}=\frac{A_{s} d_{s}+\left(E_{G F R P} / E_{s}\right) A_{G F R P} d_{G F R P}}{A_{s}+\left(E_{G F R P} / E_{s}\right) A_{G F R P}}
$$

where $d_{s}$ is the distance between the centroid of the steel bars and the top face of the section. 
In Eq. (4) $f_{G F R P, u}$ is the ultimate tensile strength of GFRP reinforcement, $\varepsilon_{c u}$ is the ultimate concrete compressive strain, assumed equal to 0.0035 in the present study. The parameter $\beta_{1}$, dependent of the concrete compressive strength $\left(f_{c m}\right)$, represents the ratio of the equivalent rectangular stress block depth to the depth of the neutral axis (for $f_{c m} \leq 30 \mathrm{MPa}, \beta_{1}=0.85$, while for $\left.f_{c m}>30 \mathrm{MPa}, \beta_{1}=0.85-\left(f_{c m}-30\right) / 7 \times 0.05\right)$. Accordingly, the effect of the stress in tensile GFRP bars, $f_{\text {GFRP }}$, and the GFRP reinforcement ratio, $\rho_{\text {GFRP }}$, are considered in the parameter " $\Gamma_{e q}$ ".

$$
\Gamma_{e q}=\frac{\left(\rho_{s} f_{s y}+\rho_{s e q, G F R P} \cdot f_{G F R P}\right)+2.32 F_{f}}{0.85 f_{c m}+3.08 F_{f}}
$$

where $\rho_{s}$ is reinforce ratio of longitudinal steel reinforcements.

The internal ultimate resisting moment at failure, $M_{u}$, which is equated to the external moment $\left(M_{u}=V_{u} \cdot a\right.$, where $V_{u}$ is the maximum shear resistance of the beam) can be predicted for fiber reinforced concrete beams flexurally reinforced with a hybrid system by using the following equation [30].

$$
M_{u}=0.6 b d_{s, e q}^{2} \psi \sqrt[3]{\omega}\left[f_{c m}^{0.44}\left(a / d_{s, e q}\right)+275 \sqrt{\omega /\left(a / d_{s, e q}\right)^{3}}\right]
$$

in which $\psi$ is size effect factor, can be calculated according to the following equation:

$$
\psi=\frac{1+\sqrt{5.08 / d_{a}}}{\sqrt{1+d /\left(25 d_{a}\right)}}
$$

where $d_{a}$ is the maximum aggregate size.

and

$$
\omega=\rho_{s, e q}\left(1+4 F_{f}\right)
$$

is a reinforcement factor where the equivalent steel reinforcement ratio, $\rho_{s, e q}$, [9] is obtained from the following equation:

$$
\rho_{s, e q}=\frac{A_{s}}{b d_{s}}+\frac{E_{G F R P}}{E_{s}} \frac{A_{G F R P}}{b d_{G F R P}}
$$


Fig. 2 represents the relation between the $M_{u} / M_{f l}$ and $a / d_{s, e q}$ for a beam with $F_{f}$ values ranging from 0 to 1 , and assuming $f_{c m}=65 \mathrm{MPa}, f_{s y}=490 \mathrm{MPa}, f_{\text {GFRP }}=897 \mathrm{MPa}, d_{s, e q}=235 \mathrm{~mm}$ and $\rho_{s, e q}=0.1 \%$ (representative values of the materials available for the experimental program). Since $M_{f l}$ is not affected by $a / d_{s, e q}$, and only $M_{u}$ changes with this parameter, two different values of $a / d_{s, e q}$ can be obtained for the same $M_{u} / M_{f l}$. Considering that $M_{u}=V_{u} \cdot a=(P / 2) . a$ (in the three point bending test), it is clear that the beam is capable of carrying higher load, $P$, when the beam has a shorter shear span and, consequently a lower $a / d_{s, e q}$ ratio, at the same level of $M_{u} / M_{f l}$. Accordingly, two different failure modes of diagonal-tension, DT, and shearcompression (or shear-tension), SC (or ST), can be addressed at two different values of $a / d_{s, e q}$ as shown in Fig. 2. The minimum relative flexural capacity of the beam, $\left(M_{u} / M_{f l}\right)_{\min }$, corresponding to only one critical shear span to effective depth ratio, $\left(a / d_{s, e q}\right)_{c}$, delimits the DT from the SC (or ST) modes of failure. Fig. 2 also indicates two limiting values, $\left(a / d_{s, e q}\right)_{R}$ at the right side, and $\left(a / d_{s, e q}\right)_{L}$ at the left side, where $M_{u} / M_{f l}=1$. Between these two limiting values, $\left(a / d_{s, e q}\right)_{L}<a / d_{s, e q}<\left(a / d_{s, e q}\right)_{R}$, the two types of shear failure govern the behavior of the beams, depending on the $a / d_{s, e q}$ ratio. The detailed description of these failure modes are represented in ASCE-ACI committee 426 [32].

\subsection{Dosage of steel fiber}

In addition to the significant effect of $a / d_{s, e q}$ on the relative flexural carrying capacity, and consequently on the shear strength of the beams (see Fig. 2), from the abovementioned formula it is clear that the relative flexural capacity of the beam is also affected by a large number of parameters, most importantly the volume fraction of the fibers. Fig. 2 illustrates the influence of the combined effect of fiber factor, $F_{f}$, and $a / d_{s, e q}$ on the relative flexural capacity of a beam $M_{u} / M_{f l}$ (the variation of $F_{f}$ is only caused by the $V_{f}$ ). The figure shows the significant increase of $M_{u}$ with the fiber factor (caused by the increase of $V_{f}$ ) compared to that of $M_{f l}$, leading to the increase of the beam's relative flexural capacity, $M_{u} / M_{f l}$. This exhibits the pronounceable effect of fibers on enhancing the shear capacity of the beam, which may successfully reduce the requirement of conventional shear reinforcements for the beams to be developed in the scope of the present research project. This idea is used 
to attain the aimed improvements in the shear strength of the short-span beams without stirrups to be tested in this experimental program.

\section{EXPERIMENTAL PROGRAM}

\subsection{SFRSCC mix design}

The mix design methodology proposed by Soltanzadeh et al. [16] was used for the development of the SFRSCC with rheological and mechanical properties suitable for the production of precast prestressed concrete elements, such as self-compacting character (SCC) and relatively high compressive and post-cracking residual strength. In accordance with this method, the concrete composition with the required dosage of steel fibers was developed by means of the following three main steps: (i) definition of the optimum proportions of constituent materials for developing the paste with an adequate flowability and viscosity without bleeding; (ii) determination of the optimum volume percentage of each type of aggregates in the granular skeleton of the concrete, in order to produce the most compact SFRSCC; and (iii) assessment of an optimum correlation between the paste and the solid skeleton in order to obtain a SFRSCC that meets the requirements of SCC in terms of flowability and filling ability, as well as the ability to resist blockage and segregation, together with the aimed mechanical performance in the harden stage in accordance with the demands of the present study for fabricating the prestress beams without stirrups.

The SFRSCC constituents are: Portland cement CEM I 42.5R, limestone filler, fly ash class F, a second-generation of superplasticizer based on polycarboxylate ether (PCE) polymers (Glenium SKY 617), water, three types of aggregates (containing fine and coarse river sand and crushed granite with maximum size of $2.4 \mathrm{~mm}, 4.8 \mathrm{~mm}$ and $12.5 \mathrm{~mm}$, respectively). The concrete was reinforced with a fiber volume fraction, $V_{f}$, of $1.1 \%$ of hooked end steel fibers with $33 \mathrm{~mm}$ length, $l_{f}$, aspect ratio $\left(l_{f} / d_{f}\right)$ of 64 , and tensile strength of $1100 \mathrm{MPa}$. The developed composition is represented in Table 1.

\subsection{SFRSCC properties}

The fresh state performance of the SFRSCC mix was characterized by means of the slump-flow test. The mix reached a spread diameter of $500 \mathrm{~mm}$ within $3.5 \mathrm{sec}\left(T_{50}\right)$, and the total spread diameter of the mix was $660 \mathrm{~mm}$. 
No visual sign of segregation was detected in the developed concrete, and the mixture presented good homogeneity and cohesion during flowing through the Abrams cone.

The mechanical performance of the SFRSCC at hardened state was evaluated by determining the Young's modulus [33], the compressive strength [34] and the flexural behavior [23] at the ages of 3, 7 and 28 days. Table 2 includes the average values of the compressive strength, $f_{c m}$, and Young's modulus, $E_{c m}$, of nine SFRSCC cylindrical specimens of $150 \mathrm{~mm}$ diameter and $300 \mathrm{~mm}$ height (three specimens at each age). The characteristic compressive strength, $f_{c k}$, is also presented in this table. The results show that the strength and stiffness have increased rapidly with age, which suggests that the developed SFRSCC is appropriate to the requirements of the prefabrication industry in terms of fast demolding of cast RC elements.

The flexural behavior of the developed concrete is assessed by determining the flexural strength and the residual flexural tensile strength parameters of the SFRSCC, $f_{R 1}$ to $f_{R 4}$, corresponding to distinct values of crack mouth opening displacement $\left(C M O D_{j}(j=1\right.$ to 4$\left.)\right)$. For this purposes, three point-bending tests on nine simply supported notched SFRSCC beams were carried out according to the recommendations of MC2010 [23]. Each series of three prismatic specimens $\left(150 \times 150 \times 600 \mathrm{~mm}^{3}\right)$ was tested after 3,7 and 28 days of casting. In these tests the stress at the limit of proportionality, $f_{c t, L}^{f}$, (related to the maximum load reached up to a CMOD of $0.05 \mathrm{~mm}$ ) and the $f_{R 1}$ to $f_{R 4}$ were obtained. These values are indicated in Table 3, and a clear tendency for their increase with the age is observed, having this increase been more pronounced at the earlier ages. According to the MC2010 [23] this SFRSCC is of toughness class "c" $\left(f_{R 3} / f_{R 1}=0.98\right)$ Fig. 3 presents the nominal flexural stress, $\sigma_{f}$, versus CMOD relationship of SFRSCC beams corresponding to the three testing ages $\left(\sigma_{f}=1.5 P /\left(b \times h_{s p}^{2}\right)\right.$, where $P$ is the applied load, and $b$ and $h_{s p}$ is the width and depth of the notched cross section of the specimens). This figure shows that the flexural strength at 28 days age has exceeded $18 \mathrm{MPa}$ up to the crack width of about 1.5 $\mathrm{mm}$, and at $3.5 \mathrm{~mm}$ of crack width this composite still presents an average flexural capacity of about $13 \mathrm{MPa}$. Above a CMOD of $2.5 \mathrm{~mm}$ the flexural stress has decreased faster in the case of the tested specimens at 28 days age compared to what happened in the specimens tested at the other ages. Similar tendency was also reported by Pereira et al. [35] and Cuenca and Serna [36]. The main reason is related to the increase of concrete tensile strength during the curing age, since once the matrix cracks, the energy accumulated in the tensile deformation of the matrix is suddenly transferred to the fibers bridging the cracks, leading to occurrence of some damage on the fiber-matrix bond mechanism that causes the aforementioned decay in the flexural stress after peak load [35]. 


\subsection{Test specimens}

The experimental program is composed of six beams of a span length, $L$, of $1050 \mathrm{~mm}$ and a rectangular cross section of $150 \mathrm{~mm}$ wide, $b$, and $300 \mathrm{~mm}$ height, $h$. Two longitudinal steel bars of $12 \mathrm{~mm}$ diameter, $\phi 12$, and one of $10 \mathrm{~mm}$ diameter, $\phi 10$, positioned at a depth of $230 \mathrm{~mm}, d_{s}$, and a ribbed GFRP rebar of $12 \mathrm{~mm}$ diameter, $\phi 12$, with a depth of $270 \mathrm{~mm}, d_{G F R P}$, were used for the flexural reinforcement. The general configuration of the beams and the arrangement of the reinforcements are represented in Fig. 4. By considering the internal arm $\left(d_{s}\right.$, $\left.d_{\text {GFRP }}\right)$ and the cross sectional area $\left(A_{s}, A_{\text {GFRP }}\right)$ of the steel and the GFRP bars, an equivalent internal arm, $d_{s, e q}$, of $235 \mathrm{~mm}$ was obtained (Eq. 5). The mechanical properties of the GFRP and steel longitudinal reinforcements are reported in Tables 4 and 5, respectively.

The prestress levels of $0 \%$ (control beam), $20 \%$ and $30 \%$ of GFRP ultimate tensile strength $\left(f_{\text {GFRP }, u}=1350 \mathrm{MPa}\right)$ were adopted for the experimental program, by respecting the recommendations of the CAN/CSA-S6-06 guideline [37] and ISIS Educational Module [38]. Table 6 presents the details of each series of fabricated beams, introduced by the label "Bi-Pj", where " $i$ " identifies the number of the tested beams in each series (two beams were tested per each series) and " $j$ " is the percentage of prestress applied to the GFRP bar.

To determine the shear span of the beams and define the best test set up, as well as the variation of the relative flexural capacity of the beam, $M_{u} / M_{f l}$, regarding to the range of the shear span to the equivalent effective depth ratio, $a / d_{s, e q}$, is studied as shown in Fig. 5. According to this figure, the critical shear span to the equivalent effective depth ratio, $\left(a / d_{s, e q}\right)_{c}$, as well as the two limiting values of $\left(a / d_{s, e q}\right)_{L}$ and $\left(a / d_{s, e q}\right)_{R}$ are, respectively, 2.77, 2.23 and 3.40 for the series of beam with the introduced reinforcing ratio and fiber volume fraction. A shear span to equivalent effective depth ratio $\left(a / d_{s, e q}\right)=2.23$ equal to the limiting value of $\left(a / d_{s, e q}\right)_{L}$ was selected for the test setup of the experimental program, by adopting $a=525 \mathrm{~mm}$. Taking into account that $a / d_{s, e q}$ ratio in the designed beams lies on the border between shear and flexural mode of failure, there is the probability of occurring the combination of shear and flexural failure rather than whether flexural or shear failure for these beams (without prestress). In two other series of beams, with $20 \%$ and $30 \%$ of prestress, the axial compression increases the depth of the uncracked compression zone, decreases the width of the shear cracks, and thus the shear stress transference is increased. It is well known that all of these factors lead to an increase in shear capacity of the beams, but how much the shear resistance is influenced by the axial prestress load was not yet addressed, as well as its influence on the failure mode of the members. 
To improve the relative flexural capacity of the designed beams, $M_{u} / M_{f l}$, as a majored aim of this study, the volume fraction of the fibers was designed by investigating the effect of the fiber factor, $F_{f}$, on both $M_{f l}$ and $M_{u}$, as formulated in Eqs. (3) and (7), respectively. According to Fig. 6, which describes the relationship between $F_{f}$ and both $M_{f}$ and $M_{u}$, the improvement of $M_{u}$ and, consequently, the shear resistance of the beam by increasing the fiber content is more pronounceable than that of the nominal flexural capacity $M_{f}$. The point at which $M_{u}=M_{f l}$ indicates the optimum fiber factor, $F_{f, o p t}$. The vertical dash line in Fig. 6 delimits the failure modes of the beams according to the $M_{u} / M_{f l}$ ratio. In the left side of this line, where $M_{u}<M_{f l}$, the fibers dosage is not sufficient to avoid shear failure, while in the right side of this line, where $M_{u}>M_{f l}$, a flexural failure mode is expected. For the present control beams, with $a / d_{s, e q}=2.23, F_{f}$ is equal to 0.69 , which corresponds to $90 \mathrm{Kg} / \mathrm{m}^{3}$ steel fibers. This optimum dosage of steel fibers was adopted for developing the beams, since it was assumed that the favorable effect of the prestress level to be applied to the GFRP bar can contribute to assure a flexural failure mode for the $\mathrm{B} i$-P20 and $\mathrm{B} i$-P30 series of beam.

\subsection{Prestressing system and fabrication of the elements}

The prestress was applied at the both extremities of the GFRP bar using hollow hydraulic cylinders with maximum capacity of $200 \mathrm{kN}$. The GFRP bars were anchored in both extremities by using an active and a passive anchor. The rate of prestressing was $0.5 \mathrm{kN} / \mathrm{min}$, and the prestressing load was monitored using a load cell placed between the bulkhead and the hydraulic cylinder. Further details of the prestressing system can be found in [39].

After arranging the reinforcements and prestressing the GFRP bars, three beams were cast using the developed SFRSCC of the same batch. For each batch three beams were cast: the reference beam, and two beams with a prestressed GFRP bar, one at $20 \%$ and the other at $30 \%$. The prestressing force was released 3 days after casting the beams, adopting a release rate of about $0.3 \mathrm{kN} / \mathrm{min}$. Curing of the beams was carried out for 7 days at an average temperature of $23^{\circ} \mathrm{C}$ and $60 \%$ humidity. The beams were tested at the age of 28 days.

\subsection{Test setup and procedure}

The three-point bending test setup adopted in the present study is illustrated in Fig. 4. The simply supported beams were subjected to a point load at the mid-span with the clear distance of $525 \mathrm{~mm}$ from each support. All the tested 
beams were loaded monotonically at a displacement rate of $10 \mu \mathrm{m} / \mathrm{s}$ up to the failure. The applied load, $P$, was assured by a servo-controlled hydraulic actuator of $\pm 700 \mathrm{kN}$ with $\pm 0.05 \%$ accuracy. To monitor the deflections at the mid-span and along the shear spans, five linear variable displacement transducers (LVDTs) were disposed according to the arrangement indicated in Fig. 4.

\subsection{Experimental results}

\subsubsection{Load-deflection relationship}

Fig. 7 represents the overall behavior of the beams in terms of load versus mid-span deflection, $P-\delta$, and the ultimate values of the load obtained by testing the beams are compared with the calculated ones corresponding to the full flexural capacity, $M_{u}=M_{f l}$. As it was expected, the flexure-shear failure was the governing mode of failure in the control beams, which was accompanied with a relatively high deflection of $11.45 \mathrm{~mm}$ (the average deflection at failure stage of the beams B1-P0 and B2-P0). The crack pattern of these beams which was continuously captured each 20 second, evidence that the flexural mode of failure was the governing failure mode in these beams up to a pronounceable deflection of $7.5 \mathrm{~mm}$ (see Appendix A). However, due to the absence of the prestress, the steel fibers could not resist the opening of the shear crack after $7.5 \mathrm{~mm}$ deflection, and thus, a critical shear crack grown rapidly leading to the failure of the beam under a combination of shear and flexure. Comparison of the relative flexural capacity obtained by testing the control beam with $90 \mathrm{Kg} / \mathrm{m}^{3}$ steel fibers with the estimated ones for the beams without steel fiber $\left(M_{u} / M_{f l}=0.53\right)$, demonstrates the pronounceable increase of $59 \%$ in the calculated relative flexural capacity by application of the optimum dosage of steel fiber.

By testing the control beams an average maximum load of $298 \mathrm{kN}$, corresponding to the ultimate moment of $M_{u, \exp }=78.32 \mathrm{kN} . \mathrm{m}$, was obtained at an average displacement of $11.45 \mathrm{~mm}$. The ratio of the ultimate moment obtained by testing the control beams, $M_{u \text { exp }}$, to that of calculated analytically, $M_{u}=60.61 \mathrm{kN} . \mathrm{m}$, shows that the ultimate moment estimated by the formula is safe but marginally conservative in the case of the control beams ( $\left.M_{u, \exp } / M_{u}=1.3\right)$. The application of the prestress in the other series of beams caused an increase of the beam's load carrying capacity and ductility performance. Hence, the prestress increased the bearing capacity of B $i$-P20 and $\mathrm{B} i$-P30 beam series respectively $8.4 \%\left(M_{u, \exp (B i-P 0)}=91.6 \% M_{u, \exp (B i-P 20)}\right)$ and $15.5 \%\left(M_{u, \exp (B i-P 0)}=84.5 \%\right.$

$\left.M_{u, \exp (B i-P 30)}\right)$ in comparison with the control specimens. Table 7 summarizes the results obtained by testing the 
beams.

\subsubsection{Modes of failure}

Fig. 8 shows the crack pattern of all the beams at the moment of failure. Regardless of the type of failure, the crack pattern of the specimens produced by the tailor-made SFRSCC with the optimum dosage of steel fibers is characterized by closely spaced cracks that appeared progressively. At the failure moment, some crushing was observed at the compression zone.

As it is already indicated the control beams, $\mathrm{B} i$-P0, failed in combination of shear and flexural mode of failure. After the formation and propagation of the first flexural cracks, the flexural mode of failure was the governing mode up to $7 \mathrm{~mm}$ deflection of the beam. By increasing the deflection, the cracks in the central region of the shear span started being progressively converted in diagonal shear ones. One of these cracks has degenerated in the shear failure crack that propagated along the longitudinal reinforcements in one extremity and towards the applied load in the other extremity. Hence, both the formed flexural and shear cracks interacted to produce the combined shear-flexural mode of failure. The failure of the beams was followed by the occurrence of splitting cracks along the steel longitudinal reinforcements. The first member of this series, B1-P0, presented a slightly better behavior in terms of load carrying capacity and ductility (herein considered deformational capacity), which may be attributed to the better dispersion and orientation of fibers.

In general the applied prestress provided a confinement in the tested beams. This confinement delayed the crack opening and, consequently caused the fibers to be later activated. Hence, the effect of prestress on the beam with higher number of fibers aliened across the crack and bridge the crack was more pronounceable. In beam B2-P20, it seems that an insufficient number of fibers were properly oriented along the beam (which can be attributed to the fiber orientation) and thus, the application of prestress in combination with the fibers for bridging the crack was not effective enough to reach the flexural failure. On the other hand, the confinement provided in beam B1P20 (with a proper fiber orientation) by application of prestress caused to increase the bridging effect of a higher number of fibers laid across the crack, leading to obtain the flexural failure. The best structural performance was observed in the beams of series B $i$-P30 that failed in bending at approximately the same load. 


\section{FINITE ELEMENT ANALISYS}

\subsection{Model description}

Finite element simulations were performed for each series of the tested beams, with $0 \%, 20 \%$, and $30 \%$ prestress applied to GFRP bar, using a plastic-damage multidirectional fixed smeared crack (PDSC) model. The PDSC model is described in detail elsewhere [40], therefore only a short resume of the model is presented. The model formulation is described at the domain of an integration point $(I P)$ of a plain stress finite element.

Modeling cracked materials using a smeared approach is usually based on the decomposition of the total incremental strain vector, $\Delta \underline{\varepsilon}$, into an incremental crack strain vector, $\Delta \underline{\varepsilon}^{c r}$, and an incremental concrete strain vector, $\Delta \underline{\varepsilon}^{c o}$, as proposed by De Borst and Nauta [41], $\left(\Delta \underline{\varepsilon}=\Delta \underline{\varepsilon}^{c o}+\Delta \underline{\varepsilon}^{c r}\right)$. Deformational contribution of the sets of smeared cracks that can be formed (according to a crack opening criterion) in an IP is considered in $\Delta \underline{\varepsilon}^{c r}$ . For modeling a cracked member with material between cracks in nonlinear compression, the term $\Delta \underline{\varepsilon}^{\text {co }}$ is further decomposed into its elastic $\left(\Delta \underline{\varepsilon}^{e}\right)$ and plastic parts $\left(\Delta \underline{\varepsilon}^{p}\right),\left(\Delta \underline{\varepsilon}^{c o}=\Delta \underline{\varepsilon}^{e}+\Delta \underline{\varepsilon}^{p}\right)$. Thereby the incremental constitutive relation of the PDSC model is obtained as:

$$
\Delta \underline{\bar{\sigma}}=\underline{D}^{e}\left(\Delta \underline{\varepsilon}-\Delta \underline{\varepsilon}^{p}-\Delta \underline{\varepsilon}^{c r}\right)
$$

being $\Delta \underline{\bar{\sigma}}=\left\{\Delta \bar{\sigma}_{1}, \Delta \bar{\sigma}_{2}, \Delta \bar{\tau}_{12}\right\}$ the incremental stress vector induced in the material due to $\Delta \underline{\varepsilon}=\left\{\Delta \varepsilon_{1}, \Delta \varepsilon_{2}, \Delta \gamma_{12}\right\}$, and considering the constitutive matrix of the intact material, $\underline{D}^{e}$.

The plastic strain vector, $\Delta \underline{\varepsilon}^{p}$, is evaluated by a time-independent plasticity model according to the following flow rule:

$$
\Delta \underline{\varepsilon}^{p}=\Delta \lambda \frac{\partial f}{\partial \underline{\bar{\sigma}}}
$$

where $\Delta \lambda$ is the non-negative plastic multiplier and $f$ is a scalar function, called yield function, that is dependent on the stress vector $\underline{\bar{\sigma}}$, and the hardening function $\bar{\sigma}_{c}$, i.e. $f=f\left(\underline{\bar{\sigma}} ; \bar{\sigma}_{c}\right)$. Hardening function carries the meaning of current uniaxial compressive stress and is dependent on the hardening parameter $\left(\tilde{\epsilon}_{c}\right)$. The hardening parameter is a scalar measure used to characterize the plastic state of the material under compressive stress field. In fact, compressive behavior of the material is governed by the uniaxial hardening law $\bar{\sigma}_{c}-\tilde{\epsilon}_{c}$ represented in Fig. 9a. In this figure $f_{c m}$ is the compressive strength, and $f_{c 0}$ is the uniaxial compression stress at the initiation of the stress-strain nonlinear behavior, defined by the $\alpha_{0}$ is a material constant i.e. 
$f_{c 0}=\bar{\sigma}_{c}\left(\tilde{\epsilon}_{c}=0\right)=\alpha_{0} f_{c m}$. Hardening parameter at the total axial strain corresponding to the compressive strength $\left(\tilde{\epsilon}_{c 1}\right)$ is obtained from the following equation:

$$
\tilde{\epsilon}_{c 1}=\varepsilon_{c 1}-f_{c m} / E_{c m}
$$

being $\varepsilon_{c 1}$ the total strain at compressive strength, and $E_{c m}$ is the elasticity modulus of concrete.

The $\Delta \underline{\varepsilon}^{c r}$ is evaluated using a multidirectional fixed smeared crack model that considers the possibility of forming more than one crack of different orientation in the same $I P$ during the cracking process. The crack initiation is governed by the Rankin failure criterion that assumes a crack occurs when the maximum principal tensile stress in an IP attains the concrete tensile strength $\left(f_{c t}\right)$ under an assumed tolerance. After crack initiation, the relationship between the normal stress and the normal strain in the crack coordinate system, i.e. $\sigma_{n}^{c r}-\varepsilon_{n}^{c r}$, is simulated via the quadrilinear diagram represented in Fig. 10 [42]. Normalized strain, $\xi_{i}(i=1,2,3)$, and stress, $\alpha_{i}(i=1,2,3)$, parameters are used to define the transition points between linear segments, being $G_{f}^{\mathrm{I}}$ the fracture energy mode I, while $l_{b}$ is the characteristic length (crack bandwidth) used to assure that the results of a material nonlinear analysis is not dependent of the refinement of the finite element mesh.

The model simulates the shear behavior of the cracked concrete according to two methods:

1) using an incremental crack shear stress-shear strain approach based on a shear retention factor ( $\beta$ approach). According to this approach, the crack shear stress $\left(\tau_{t}^{c r}\right)$ increases with the crack shear strain $\left(\gamma_{t}^{c r}\right)$ up to attain a maximum that depends on the crack shear modulus ( $D_{t}^{c r}$ ), see Fig. 11a [43]. The modulus $D_{t}^{c r}$ is simulated as:

$$
D_{t}^{c r}=\frac{\beta}{1-\beta} G_{c}
$$

where $G_{c}$ is the concrete elastic shear modulus, while the shear retention factor, $\beta$, can be a constant value or, alternatively, as a function of current crack normal strain, $\varepsilon_{n}^{c r}$, and of ultimate crack normal strain, $\varepsilon_{n, u}^{c r}$, such as:

$$
\beta=\left(1-\frac{\varepsilon_{n}^{c r}}{\varepsilon_{n, u}^{c r}}\right)^{P_{1}}
$$

being the exponent $P_{l}$ a parameter that defines the decrease rate of $\beta$ with increasing $\varepsilon_{n}^{c r}$.

In the current approach the $D_{t}^{c r}$ decreases with the increase of $\varepsilon_{n}^{c r}$, but the crack shear stress $\left(\tau_{t}^{c r}\right)$ can continuously increase (Fig. 11a) and attain values much higher than the concrete shear strength according to available experimental data and design guidelines. 
2) adopting a $\tau_{t}^{c r}-\gamma_{t}^{c r}$ softening law to simulate more correctly the shear stress transfer during the crack opening process, which allows better predictions in terms of load carrying capacity, deformability, and crack pattern of RC elements failing in shear [42]. The adopted shear softening law is represented in Fig. 11b, and can be formulated by the following equation [42]:

$$
\tau_{t}^{c r}= \begin{cases}D_{t, 1}^{c r} \gamma_{t}^{c r} & 0<\gamma_{t}^{c r} \leq \gamma_{t, p}^{c r} \\ \tau_{t, p}^{c r}-\frac{\tau_{t, p}^{c r}}{\gamma_{t, u}^{c r}-\gamma_{t, p}^{c r}}\left(\gamma_{t}^{c r}-\gamma_{t, p}^{c r}\right) & \gamma_{t, p}^{c r}<\gamma_{t}^{c r} \leq \gamma_{t, u}^{c r} \\ 0 & \gamma_{t}^{c r}>\gamma_{t, u}^{c r}\end{cases}
$$

where $\tau_{t, p}^{c r}$ is the crack shear strength (shear stress at peak), $\gamma_{t, p}^{c r}=\tau_{t, p}^{c r} / D_{t, 1}^{c r}$ is the crack shear strain at $\tau_{t, p}^{c r}$, and $\gamma_{t, u}^{c r}$ is the ultimate crack shear strain:

$$
\gamma_{t, u}^{c r}=\frac{2 G_{f, s}}{\tau_{t, p}^{c r} l_{b}}
$$

being $G_{f, s}$ the fracture energy mode II. The inclination of the hardening branch of diagram, $D_{t, 1}^{c r}$ (see Fig. 11b), is defined by Eq. (14) where $\beta$ is set as a constant value in the range $] 0,1[$. More details corresponding to the crack shear softening diagram can be found elsewhere [42].

Once the $\Delta \underline{\bar{\sigma}}$ is calculated from Eq. (11) at a generic $n+1$ loading stage, the stress vector at this stage is updated $\left(\underline{\bar{\sigma}}_{n+1}=\underline{\bar{\sigma}}_{n}+\Delta \overline{\bar{\alpha}}_{n+1}\right)$. The stress vector $\overline{\bar{\alpha}}_{n+1}$ does not take into account the strain softening of the material under compression since the adopted $\bar{\sigma}_{c}-\tilde{\epsilon}_{c}$ law (Fig. 9a) is always in the hardening phase, i.e. the $\bar{\sigma}_{c}-\tilde{\epsilon}_{c}$ law does not include a softening branch. To simulate the strain softening and stiffness degradation of the material under compression, an isotropic damage law is included according to the following equation [40]:

$$
\underline{\sigma}_{n+1}=\overline{\bar{\sigma}}_{n+1}^{+}+\left(1-d_{c, n+1}\right){\underline{\overline{\sigma_{n+1}}}}_{n}^{-}
$$

where $\underline{\sigma}_{n+1}$ is the stress vector in damaged, respect to compression, configuration, and $\underline{\bar{\sigma}}_{n+1}^{+}$and $\overline{\bar{\sigma}}_{n+1}^{-}$are the positive (tensile) and the negative (compressive) parts of the un-damaged, respect to compression, stress vector ( $\left.\overline{\bar{\sigma}}_{n+1}\right)$. The variable $d_{c}$ is a scalar measure in the range $[0,1]$ that is used to represent the damage level due to compression. Fig. $9 \mathrm{~b}$ represents the evolution of the scalar damage variable $\left(d_{c}\right)$ as a function of the plasticity hardening variable $\left(\tilde{\epsilon}_{c}\right)$. It is verified that at the plastic deformation corresponding to $\tilde{\epsilon}_{c} \leq \tilde{\epsilon}_{c 1}$ the material is intact ( $\left.d_{c}=0\right)$, and for $\tilde{\epsilon}_{c}=\tilde{\epsilon}_{c u}$ the material is completely damaged $\left(d_{c}=1\right)$. The variable $\tilde{\epsilon}_{c u}$ is the maximum 
equivalent strain in compression that is related to the compressive fracture energy $\left(G_{f, c}\right)$, the crack bandwidth ( $\left.l_{b}\right)$, the compressive strength $\left(f_{c m}\right)$, and $\tilde{\epsilon}_{c 1}$ according to the following equation [40]:

$$
\tilde{\epsilon}_{c u}=\frac{3.1 G_{f, c}}{l_{b} f_{c}}-\frac{11}{48} \tilde{\epsilon}_{c 1}
$$

\subsection{FEM modeling, results and discussions}

The finite element mesh of 8 -noded plain stress finite elements with $3 \times 3$ Gauss-Legendre $I P$ scheme, represented in Fig. 12, was adopted for the beams (the differences between beams in different series are limited to the prestress load applied to the GFRP bar). The longitudinal steel and GFRP bars were modeled using 2-noded truss elements (one degree-of-freedom per each node) with two IPs. Perfect bond was assumed between the reinforcement bars and the surrounding concrete. For modeling the behavior of the steel bars, the stress-strain relationship represented in Fig. 13 was adopted. The curve (under compressive or tensile loading) is defined by the points PT1 $=\left(\varepsilon_{s y}, \sigma_{s y}\right.$ ) , PT2 $=\left(\varepsilon_{s h}, \sigma_{s h}\right)$, and PT3 $=\left(\varepsilon_{s u}, \sigma_{s u}\right)$ and a parameter $P_{s}$ that governs the shape of the last branch of the curve. Unloading and reloading linear branches with slop of $E_{s}=\sigma_{s y} / \varepsilon_{s y}$ are assumed in the present approach [44]. The behavior of GFRP bar was modeled using a linear-elastic stress-strain relationship defined by the values indicated in Table 4. The prestress load was simulated by means of temperature variation applied to the truss elements modeling the GFRP bar. Table 8 represents the values of the temperature variation applied to each simulated beam. The values of parameters used to define the constitutive models of steel and concrete (FRSCC) are included in Table 9 and Table 10, respectively. To define the crack shear stress-shear strain diagram $\left(\tau_{t}^{c r}-\gamma_{t}^{c r}\right.$ ), represented in Fig. 11b, the values of the corresponding parameters, included in Table 10, were obtained by simulating the experimental results of the reference beams ( $\mathrm{Bi}-\mathrm{P} 0)$ as best as possible. Then the same values of the parameters of the constitutive model were adopted for the prestressed beams (Bi-P20, and Bi-P30).

The experimental and the numerical relationships between the applied load and the deflection at the mid-span for all the beam series are compared in Fig. 14. In Fig. 15 the numerical crack patterns of these beam series at the end of the analysis (at the end of the last converged load increment) are compared with the obtained experimental crack patterns. These two figures show that the numerical model is able to capture with good accuracy the deformational response of the beams and captured profile of the failure crack.

The predicted strain in steel reinforcement (at the closest $I P$ of the symmetric axis of the beams) versus the midspan displacement corresponding to each simulation is represented in Fig. 16. These curves demonstrate that at a 
deflection of about $2.3 \mathrm{~mm}$ the longitudinal steel reinforcements of all the beam series (Bi-P0, Bi-P20, Bi-P30) started yielding, which indicates that the methodology described in section 2 to evaluate the content of steel fibers capable of assuring yield initiation of longitudinal reinforcement before the occurrence of beam's shear failure is reliable.

The numerically predicted relationship between the applied load and the deflection at the mid-span for all the beam series are gathered in Fig. 17. The points at crack initiation and at yield initiation of the steel reinforcement also are represented in this figure by using markers, demonstrating that by both the load at crack initiation and at yield initiation of steel reinforcements increase with the prestress level.

\section{SHEAR RESISTANCE}

In the present section, the shear resistance of the tested beams is compared with the ones predicted according to the formulations presented in the MC2010 [23], RILEM TC 162-TDF [25] and the formula proposed by Soetens [1]. In the MC2010 [23] and in the RILEM TC 162-TDF [25] approaches the shear resistance of fiber reinforced concrete beams, $V_{R d}$, is calculated as follow:

$$
V_{R d}=\left(V_{c d}+V_{f d}\right)+V_{w d}
$$

where $V_{c d}, V_{f d}$ and $V_{w d}$ are the contribution of concrete, fiber reinforcement and steel stirrups, respectively. According to the RILEM TC 162-TDF [25] approach, the shear resistance of a FRC beam without stirrups comprises the shear resistance provided by concrete, $V_{c d}$ :

$$
V_{c d}=\left[\frac{C_{1}}{\gamma_{c}} k\left(100 \rho_{s} f_{c k}\right)^{1 / 3}+0.15 \sigma_{c p}\right] b d
$$

and the shear resistance related to the contribution of steel fiber reinforcement, $V_{f d}$ :

$$
V_{f d}=0.7 k_{f} k \frac{C_{1} f_{R 4}}{\gamma_{c}} b d
$$

In Eqs. (21) and (22) $C_{1}=0.18, \gamma_{c}$ is the partial safety factor for the concrete without fibers, and $k$ is a factor that takes into account the size effect:

$$
k=1+\sqrt{200 / d} \leq 2.0(\mathrm{~d} \text { in } \mathrm{mm})
$$


In Eq. (21) $\sigma_{c p}=N_{s d} / A_{c}<0.2 f_{c k} / \gamma_{c}$ is the average stress acting on the concrete cross section, $A_{c}$, for an axial force, $N_{s d}$, due to loading or prestressing actions ( $N_{s d}>0$ for compression).

In Eq. (22) $k_{f}$ is a factor for taking into account the contribution of the flanges in a $\mathrm{T}$ and I cross sections for the shear resistance:

$$
\begin{aligned}
& k_{f}=1+n \cdot\left(h_{f} / d\right) \cdot\left(h_{f} / d\right) \leq 1.5 \\
& n=\left(b_{f}-b\right) / h_{f} \leq 3 \text { and } n \leq\left(3 b / h_{f}\right)
\end{aligned}
$$

where $h_{f}$ and $b_{f}$ are the height and width of the flange, respectively.

To determine the shear resistance of this type of FRC RC beams, the MC2010 [23] merges the contribution of fiber reinforcement, $V_{f d}$, and concrete, $V_{c d}$, in an unique term, $V_{R d, F}$, thereby Eq. (20) is reduced to:

$$
V_{R d}=V_{R d, F}+V_{w d}
$$

where,

$$
\begin{aligned}
& V_{R d, F}=\left[\frac{C_{1}}{\gamma_{c}} k\left(100 \rho_{s} C_{2} f_{c k}\right)^{1 / 3}+0.15 \sigma_{c p}\right] b d \\
& C_{2}=1+7.5 \frac{f_{\text {Ftuk }}}{f_{c t k}}
\end{aligned}
$$

being $f_{\text {Ftuk }}$ the characteristic value of the ultimate residual tensile strength of FRC.

The $V_{R d, F}$ is assumed to be not smaller than the value provided by:

$$
V_{R d, F \min }=\left[0.035 k^{3 / 2} f_{c k}^{1 / 2}+0.15 \sigma_{c p}\right] b . d
$$

Both guidelines address the contribution of the transversal reinforcement, $V_{w d}$, in the same way. Since no stirrups were used in the tested beams, this term, $V_{w d}$, is considered to be null.

The approach proposed by Soetens [1] can be written in the following general form:

$$
V_{\text {Soetens } 2015}=\left(A \sqrt{f_{c m}}+B f_{\text {Ftmu }}\right) b_{w} z
$$

where the first term represents the concrete contribution for the shear resistance of the FRC beams. The factor " $A$ " in this term is a function of the parameters assumed as having the highest influence for the reinforced concrete 
shear resistance, namely the effective depth of the beams, $d$, the longitudinal reinforcement ratio, $\rho_{s}$, the shear span to effective depth ratio, $a / d$, and the compressive stress due to the application of prestress, $\sigma_{c p}$. The second term of Eq. (28) considers the contribution of the fiber reinforcement for the shear resistance of a FRC beam. The factor " $\mathrm{B}$ " in this term is a function of the inclination of the compressive strut " $\theta$ " and of the fiber reinforcement effectiveness factor, represented by the parameter " $\alpha_{\text {red }}$ ". In this term, “ $f_{\text {Ftum }}$ " is the average ultimate postcracking tensile strength of FRC, calculated according to the following equation:

$$
f_{F t u}^{*}=\min \left\{\begin{array}{c}
f_{F t u m} \\
f_{c t m}\left(1-2 \sigma_{c p} / f_{c m}\right)
\end{array}\right.
$$

where $f_{\text {Ftum }}$ is the average ultimate post cracking tensile strength of FRC. The final configuration of Eq. (28) is the following one:

$$
V_{\text {Soetens } 2015}=\left[0.388 \sqrt{1+\frac{\sigma_{c p}}{f_{c k}}} k\left(3 \frac{d}{a} \rho_{s}\right)^{1 / 3} \sqrt{f_{c m}}+f_{F t u}^{*}\left(1+4 \frac{\sigma_{c p}}{f_{c k}}\right)\right] b_{w} z
$$

Table 11 includes the shear resistance of the tested beams, $V_{\exp }$, and corresponding shear strength, $v_{u}=V_{\exp } /\left(b d_{s, e q}\right)$, as well as the estimated values of shear resistance according to MC2010 [23], $V_{M C 2010}$, and RILEM TC 162-TDF [25], $V_{\text {RILEM }}$, and Soetens [1] approach, $V_{\text {Soetens } 2010}$. For the calculations of $V_{M C 2010}$, $V_{\text {RILEM }}$ and $V_{\text {Soetens } 2010}$ average values were considered for the material properties, and $\gamma_{c}=1$ was adopted. For the beams reinforced with hybrid GFRP-steel bars, $d$ is substituted by the equivalent steel depth, $d_{s, e q}$, presented in Eq. (5), and $\rho_{s}$ is replaced by the equivalent steel reinforcement ratio, $\rho_{s, e q}$, determined according to Eq. (10). The ratios of the shear resistance obtained experimentally to the estimated ones, $V_{\exp } / V_{\text {RILEM }}$, are also compared in this table. The $V_{\text {exp }} / V_{\text {RILEM }}$ ratio, which was very close to the unit value, suggests that RILEM [25] approach estimates more accurately the shear resistance of SFRSCC short-span beams than the other approaches. The shear resistance calculated using the formula proposed by Soetens [1], however, is only $17 \%$ higher than the values obtained experimentally. On the other hand the MC2010 [23] provides quite conservative estimations, with an average $V_{\exp } / V_{M C 2010}$ of 1.66 . The calculated values according to this approach are, in average terms, leastwise 39\% lower than the ones calculated by RILEM [25] provisions, and 47\% lower than Soetens [1] formula. The effect of prestress on the shear resistance of the beams is one of the factors considered by these formulations. In both MC2010 [23] and RILEM [25] approaches the shear resistance provided by prestressing the beams is 
evaluated by the same term " $0.15 \sigma_{c p} b d$ ", while in Soetens [1] formula the term " $\sqrt{1+\left(\sigma_{c p} / f_{c t k}\right)}$ " has this purpose. The effect of the inclination of the shear $\mathrm{crack}$ " $\cot \theta$ " is indirectly considered in the second term of the formula, " $1+4\left(\sigma_{c p} / f_{c k}\right)$ ". The influence of the prestress level on the shear resistance predicted by the three considered approaches is compared in Fig. 18a, by also indicating the results obtained experimentally. Although in the experimental tests the shear resistance of the beams was improved $15.6 \%$ by the application of $30 \%$ prestress ( $\sigma_{c p}=1 \mathrm{MPa}$ ), only $3.3 \%, 5.4 \%$ and $6.2 \%$ is the predicted increase provided by RILEM [25], MC2010 [23] and Soetens [1] approaches, respectively.

Additionally, since for the beams of series B $i$-P30 failed in bending the shear capacity was not fully mobilized, the $V_{\exp } / V_{\text {anal }}$ value was expected to be less than unit, which did not, however, occur in the predictions of MC2010 [23] and RILEM [25] approaches. Based on the obtained experimental results, it seems that the estimation of prestressing effect on the shear resistance of FRC elements requires specific research in this subject for assuring more reliable predictions.

Comparison of Eq. (21), proposed by RILEM [25], with Eq. (26) recommended by MC2010 [23], shows that the effect of fibers in Eq. (26) is only reflected on parameter " $C 2$ ". In Eq. (26) is assumed to model the shear contribution of fibers by modifying the longitudinal reinforcement ratio [45] through the factor $C 2$ that includes a parameter representative the post-cracking performance of FRC at ultimate crack width of $1.5 \mathrm{~mm}, f_{\text {Ftuk }}$. In order to estimate how the fiber effects are taken into account according to MC2010 [23] approach, the shear resistance of plain concrete was calculated, keeping $C 2=1$ (which means $f_{\text {Ftuk }}=0$ ). By subtracting the obtained value from the estimated shear resistance of FRC, the fiber contribution was evaluated. Fig. 18b compares the average shear resistance provided by fiber reinforcement, $V_{f d}$, in accordance with MC2010 [23], RILEM TC 162-TDF [25] and Soetens [1] approaches. It is verified that the contribution of steel fibers for the shear capacity of the beams is estimated 59\% lower by MC2010 [23] approach compared to the one calculated according to the RILEM [25] formulation. This figure evidences that MC2010 [23] underestimates significantly the contribution of fiber reinforcement for the shear resistance, regardless the prestress levels considered.

In the Eqs. (28) to (30) of the Soetens [1] approach the concrete, $V_{c d}$, and fiber contribution, $V_{f d}$, for the shear resistance of the FRC beams are estimated by the functions A and B, respectively, and the obtained values are compared in Fig. 18b to those determined from the RILEM [25] and MC2010 [23] approaches. This comparison shows that the Soetens [1] approach predicts the highest contribution of the fiber effects, respectively, $67 \%$ and 
19\% higher than the calculated ones by MC2010 [23] and RILEM [25] approaches, when estimating the shear resistance of FRC beams.

Fig. 18b evidences that the significant difference on the estimation of shear resistance of the beams is related to distinct calculation of $V_{f d}$. Since all the tested beams were reinforced with the same content of steel fibers, the accuracy of the estimation of fiber contribution for the shear resistance of the beams cannot be evaluated using exclusively the present experimental results. To have a better assessment of the predictive performance of the three approaches, and a deeper analysis of the influence of fibers on the shear resistance of the beams, the experimental results of twenty beams without stirrups were collected from literature. This database includes regular and high strength concrete reinforced with different content of hooked end steel fibers of aspect ratio ( $\left.l_{f} / d_{f}\right)$ in the interval 62 to 65 . The ranges of other considered parameters are as follow:

- Height of the beam's cross section: $300 \mathrm{~mm} \leq h \leq 1500 \mathrm{~mm}$;

- Cylindrical average concrete compressive strength: $32 \mathrm{MPa} \leq f_{c m} \leq 65 \mathrm{MPa}$;

- Fiber volume fraction: $0 \% \leq V_{f} \leq 1.1 \%$;

- $\quad$ Longitudinal tensile reinforcement ratio: $0.7 \% \leq \rho_{\text {eff }} \leq 1.83 \%$, and

- $\quad$ Shear span to effective depth ratio: $2.23 \leq a / d \leq 3.9$.

All the beams selected from the literature are introduced in Table 12. The beams were labeled as Chi-Fj-P/x, where: "C" can be replaced by the type of the beam's cross section, indicating if the beam has a rectangular (R), T-shape (T) or I-shape (I) cross section; " $i$ " represents the height of the beam's cross section in mm, and " $j$ " is the applied dosage of steel fiber $\left(\mathrm{kg} / \mathrm{m}^{3}\right)$. When a member is not prestressed " $\mathrm{P}$ " is dropped from its designation. Finally a number $(x)$ is assigned to each beam in order to distinguish the specimens with the similar depth, fiber dosage and prestressing condition. For instance, "Th750-F60-P/1" refers to a prestressed beam number 1 of Tshape cross section with $750 \mathrm{~mm}$ height, reinforced with $60 \mathrm{~kg} / \mathrm{m}^{3}$ of steel fibers. Additional information about the beams can be found in Appendix B. The analytical shear values corresponding to the contribution of concrete and fibers for the shear resistance of the selected beams according to the three considered approaches are indicated in Fig. 19. In this figure the calculated values for the two groups of beam, with and without prestress, are sorted in ascending order regarded to the dosage of steel fiber and are compared to the reported results obtained experimentally. Regarding the values given in Table 12 and represented in Fig.19, it can be found that RILEM 
[25] formula yields more accurate predictions for the presented sample of test data in comparison with the two other shear models, in terms of the predicted load and coefficient of variation. Hence, it can be concluded that RILEM [25] formula gives more accurate predictions of fiber contribution compared to MC2010 [23] formula, since the contribution of concrete is estimated similarly according to both these guidelines.

Fig. 20 presents the $V_{\text {exp }} / V_{\text {anal }}$ results obtained with the three approaches for the data base organized in two groups: non-prestressed beams; prestressed beams. For each of these two groups, the results are organized according to the content of fibers, and each group of beams of equal fiber content is composed of beam's of different cross section height. The results show that for the non-prestressed beam, by increasing the depth of the beam's cross section, the $V_{\exp } / V_{\text {anal }}$ has a tendency to decrease, which means that shear resistance is overestimated. For instance, while the obtained shear value for Rh500-F50/5 beam is suitably close to the experimental value and is quite safe, it becomes rather unsafe by increasing the depth of the beam's cross section (e.g. compare the predicted shear resistance values of the beam Rh500-F50/5 with that of Rh1000-F50/8 and Rh1500-F50/11 respectively). This confirms the requirement of improving size effect factor, $k$, to boost the reliability of the predictions. In the case of prestressed beams, conservative values were generally obtained by using MC2010 [23] formula ( $V_{\exp } / V_{\text {anal }}>1$ ). The experimental results were predicted adequately by using the RILEM [25] approach, while mostly were found to be marginally overestimated by Soetens [1] formula. The decrease of $V_{\exp } / V_{\text {anal }}$ with the increase of the depth of the beam's cross section seems to be well fitted by a polynomial curve, is shown clearly in Fig. 21.

For the flanged beams, the RILEM [25] approach estimates the contribution of the flange for the shear resistance by introducing the $k_{f}$ factor in its formula. For the beams with rectangular cross section, the $k_{f}$ is assumed to have unit value, while this value increases for the flanged beams, according to the equations (24a) and (24b). The variation of the safety margin obtained for the flanged beams, presented in Table 12, with and without considering the $k_{f}$ factor is compared in Fig. 22. This figure shows that, using the $k_{f}$ factor equal to one results in a better estimation of shear resistance (compared to that of estimated by accounting $k_{f}=1.31$ in accordance with RILEM [25] provision) for the beams Ih500-F90/16, Ih500-F90-P/17, Ih500-F90-P/18, Ih500-F90-P/19 and Ih500-F90$\mathrm{P} / 20$ with flange to web width ratio, $W_{f} / W_{w}$, of 2.85 . In case of the other beams, with larger $W_{f} / W_{w}$ ratio, namely 4 and 6 , with $k_{f}=1.5$, the estimation is more accurate by using the $k_{f}$ value, proposed by RILEM [25] approach. 
A similar observation was reported by Cuenca and Serna [36] when estimating the shear resistance of nine beams with T-shape cross section and $W_{f} / W_{w}$ of $2.6,4$ and 6 by adopting $k_{f}=1$ as well as the calculated $k_{f}$ factor by Eq. (24a). These researchers have verified that application of the calculated $k_{f}$ factor by Eq. (24a) for predicting the shear resistance of the beams with $W_{f} / W_{w} \geq 4$ increases the accuracy of the estimations ( $V_{\exp } / V_{\text {anal }}$ has varied from 1.3 to 1.5 in the present research), while adopting $k_{f}=1$ resulted in a better estimation of the shear resistance of the beams with $W_{f} / W_{w}<4$. The results presented in Fig. 22, as well as those reported by Cuenca and Serna [36] demonstrate the requirement of modifying the equations (24a) and (24b) in order to consider the $W_{f} / W_{w}$ ratio in calculating the $k_{f}$ factor. Fig. 22 also demonstrates an abrupt increasing of $V_{\text {exp }} / V_{\text {anal }}$ from beam Ih500-F90-P/20 to beam Th750-F60-P/3. This jump is not only due to the increase of the $W_{f} / W_{w}$ ratio, but would be also caused by a combination of the size effect and prestress level.

\section{CONCLUSION}

Three series of short-span beams with hybrid GFRP-steel flexural reinforcement and including a relatively high dosage of steel fibers (steel fiber reinforced self-compacting concrete - SFRSCC), capable of assuring the yield initiation of the steel bars, were designed and tested. To assess the effectiveness of prestress for the increase of the shear resistance and the ductility level of the failure modes of these members, the behavior of these beams were studied experimentally and numerically. Based on the results obtained in the present study, and considering those derived from the analysis of beams tested by other researchers, collected in a data base, the reliability of existing analytical approaches for estimating the shear resistance of the beams was investigated. A summary of remarks can be drawn as follow:

- Application of prestress in SFRSCC beams without stirrups provides significant increase in their shear resistance and tends to increase the ultimate flexural capacity, $M_{u}$, up to $16 \%$ of that in the control beams. Hence, the mode of failure was enhanced and changed from a flexure/shear failure mode (yield initiation followed by the formation of a critical diagonal crack) in the control beams to the flexural failure mode in the case of the beams with $30 \%$ prestress.

- A numerical approach capable of capturing the deformation response as well as the crack pattern developed in this type of RC members was adopted to demonstrate the benefits of fiber reinforcement and prestress level 
on the load carrying capacity at serviceability limit state conditions and at steel yield initiation. These numerical studies also demonstrated the applicability of the analytical approach developed for estimating the fiber reinforcement content capable of assuring ductile failure modes for this type of beams.

- $\quad$ By comparing the shear resistance estimated by RILEM [25], MC2010 [23] and Soetens [1] approaches, it was verified that all the formulations demonstrated acceptable accuracy for design of the beams without prestress. In the case of the prestressed beams RILEM [25] approach provided more accurate predictions. The shear capacity of the prestressed beams obtained by MC2010 [23] was found quite low compared to that of calculated experimentally, which should be received more attention according to the economical point of view.

- Comparing the estimated shear resistance of the beams fabricated with a same dosage of fibers and equal ratio between shear span and cross section effective depth, $a / d$, a reduction on the safety margin was obtained with the increase of the depth of the beams ( $V_{\exp } / V_{\text {anal }}$ has decreased). This demonstrates the requirement for improving the size effect factor " $k$ " in order to assure safer predictions of the shear capacity of deeper beams.

- For the development of a design approach of higher predictive performance than the ones analyzed in the present work, the effects that influence the shear capacity of RC beams should be comprehensibly evaluated, which requires the collection of a relatively large data base and its analysis with sophisticated algorithms, like data mining, as well as the execution of parametric studies with advanced FEM-based constitutive models capable of simulating the relevant phenomena involved.

\section{ACKNOWLEDGEMENTS}

The first and second authors respectively acknowledge the research grant in the ambit of the research projects "Inotec", with reference number 23024, supported by the European Regional Development Fund (FEDER), and “SlabSys-HFRC”, with reference PTDC/ECM/120394/2010, supported by the Portuguese Foundation for Science and Technology (FCT). The authors also thank the collaboration of the following companies: Sireg and Schoeck for providing the GFRP rebars, Casais to manufacture the moulds, Ibermetais for supplying the steel fibres, Secil/Unibetão for providing the Cement, and BASF for supplying the superplasticizer. 


\section{$\underline{\text { Appendix A }}$}

Comparison of the experimental crack pattern at the deflection corresponding to $7.5 \mathrm{~mm}$ with the one at failure stage for the beam B2-P0 is provided in Fig. A.1.

\section{Appendix B.}

Table B.1 provides additional information corresponding to the beams collected from literature.

\section{REFERENCES}

[1] Soetens T. Design models for the shear strength of prestressed precast steel fiber reinforced concrete girders. Doctoral Thesis: Ghent University, Belgium, 2015.

[2] Voo Y, Poon W, Foster S. Shear Strength of Steel Fiber-Reinforced Ultrahigh- Performance Concrete Beams without Stirrups. Journal of Structural Engineering 2010; 136(11): 1393-1400.

[3] Cucchiara C, Mendola LL, Papia M. Effectiveness of stirrups and steel fibers as shear reinforcement. Journal of Cement and Concrete Composites 2004; 26(7): 777-786.

[4] Ferrar L, Park Y, Shah SP. A method for mix-design of fiber-reinforced self-compacting concrete. Journal of Cement and Concrete Research 2007; 37(6):957-971.

[5] Barros JAO, Lourenço LAP, Soltanzadeh F, Taheri M. Steel-fiber reinforced concrete for elements failing in bending and in shear. European Journal of Environmental and Civil Engineering 2013; 18(1): 33-65.

[6] Brandt AM. Fiber reinforced cement-based (FRC) composites after over 40 years of development in building and civil engineering. Journal of Composite Structures 2008; 86: 3-9.

[7] Aiello MA, Ombres L. Structural performance of concrete beams with hybrid (fiber-reinforced polymer-steel) reinforcements. Journal of Composites for Construction 2002; 6(2):133-140.

[8] Kara IF, Ashour AF, Köroğlu MA. Flexural behavior of hybrid FRP/steel reinforced concrete beams. Journal of Composite Structures 2015; 129: 111-121.

[9] Qu W, Zhang X, and Huang H. Flexural behavior of concrete beams reinforced with hybrid (GFRP and steel) bars. Journal of Composites for Construction 2009; 13(5): 350-359.

[10] Sharbatdar MK. Monotonic and cyclic loading of new FRP reinforced concrete cantilever beams. International Journal of Civil Engineering 2008; 6(1): 58-71.

[11] Rezazadeh M, Costa I, Barros JAO. Influence of prestress level on NSM CFRP laminates for the flexural strengthening of RC beams. Journal of Composite Structures 2014; 116: 489-500.

[12] Achilides Z, Pilakoutas K. Bond behavior of fiber reinforced polymer bars under direct pullout condition. Journal of Composites for Construction 2004; 8(2):173-181.

[13] Al-Mahmoud F, Castel A, Francois R, Tourneur C. Effect of surface pre-conditioning on bond of carbon fiber reinforced polymer rods to concrete. Cement and Concrete Composites Journal 2007; 29(9): 677-689.

[14] Mazaheripour H, Barros JAO, Sena-Cruz JM, Soltanzadeh F. Analytical bond model for GFRP bars to steel fiber reinforced self-compacting concrete. Journal of composites for construction 2013, 17( 6).

[15] Lau D, Pam HJ. Experimental study of hybrid FRP reinforced concrete beams. Journal of Engineering 
Structures 2010; 32(12): 3857-3865.

[16] Soltanzadeh F, Barros JAO, and Santos RFC. High performance fiber reinforced concrete for the shear reinforcement: Experimental and numerical research. Journal of Construction and Building Materials 2015; 77: 94-109.

[17] Barros JAO, Taheri M, Salehian H, Mendes PJD. A design method for fiber reinforced concrete beams prestressed with steel and FRP bars. Journal of Composite Structures 2012; 94: 2494-2512.

[18] Soltanzadeh F, Mazaheripour H, Barros JAO, Taheri M, and Sena-Cruz JM. Experimental study on shear behavior of HPFRC beams reinforced by hybrid pre-stressed GFRP and steel bars. Proceedings of the 7th International Conference on FRP Composites in Civil Engineering (CICE 2014), Vancouver, Canada, 20-22 August 2014.

[19] Rao GA, Injaganeri SS. Evaluation of size dependent design shear strength of reinforced concrete beams without web reinforcement. Journal of Indian Academy of Sciences Sadhana 2011, 36(3): 393-410.

[20] Cho SH, and Kim YI. Effects of steel fibers on short beams loaded in shear. ACI Structural Journal 2003; 100(6), 765-774.

[21] ACI Committee 544.1R-96. State-of-the-Art Report on Fiber Reinforced Concrete. ACI committee report, 1996. p. 66

[22] EUROCODE 2. Design of concrete structures -Part 1-1: General rules and rules for buildings. UNI-ENV 1992-1-2, 2004.

[23] CEB-FIP Model Code 2010 - Final draft, 2011.

[24] ACI Committee 318-11. Building code requirements for structural concrete and commentary. Farmington Hills (MI): American Concrete Institute, 2006. 44 pp.

[25] RILEM TC162-TDF. Test and design methods for steel fiber reinforced concrete, $\sigma-\varepsilon$ design method. Final Recommendation. Journal of Material and Structures 2003; 35:560-567.

[26] Khuntia M, Stojadinovic B, Goel S. Shear strength of normal and high-strength fiber reinforced concrete beams without stirrups. ACI Structural Journal 1999; 96(2): 282-289.

[27] Imam M, Vandewalle L, and Mortelmans F. Shear-moment analysis of reinforced high strength concrete beams containing steel fibers. Canadian Journal of Civil Engineering 1995, 22(2): 462-470.

[28] Ashour S, Hasanain G, Wafa F. Shear behavior of high-strength fiber reinforced concrete beams. ACI Structural Journal 1992; 89(2): 176-184.

[29] Narayanan R, Darwish I. Use of steel fiber as shear reinforcement. ACI Structural Journal 1987; 84(3): 216227.

[30] Imam M, Vandewalle L, Mortelmans F, and Van GD. Shear domain of fiber-reinforced high-strength concrete beam. Journal of Engineering structures 1997; 19(9): 738-747.

[31] ACI440.IR-06. Guide for the Design and Construction of Structural Concrete Reinforced with FRP Bars. ACI committee report, 2006. p. 44.

[32] ASCE-ACI Committee 426. The shear strength of reinforced concrete members. Journal of Structural Division 1973; 99(6): 1091-1187.

[33] BS EN 12390-13. Testing hardened concrete-Part 13: determination of secant modulus of elasticity in compression, 2014.

[34] ASTM C39/C39M-14a. Standard test method for compressive strength of cylindrical concrete specimens. 
Annual Book of ASTM Standard, American Society of Testing Materials, 2014. DOI: 10.1520/C0039M-14A.

[35] Pereira EN, Barros JAO, and Camoes A. Steel fiber-reinforced self-compacting concrete: experimental research and numerical simulation. Journal of structural engineering 2008; 134(8): 1310-1320.

[36] Cuenca E, and Serna P. Shear behavior of prestressed concrete beams made of self-compacting fiber reinforced concrete. Journal of construction and building materials 2013; 45:145-156.

[37] CAN/CSA-S06-06. The Canadian Highway Bridge code (CHBDC), Canadian Standards Association, Ottawa, Ontario, Canada, 2006.

[38] ISIS Canada. A Canadian Network of Centres of Excellence. ISIS Educational Module 9: Prestressing Concrete Structures with Fibre Reinforced Polymers 2007; 10:2(139).

[39] Soltanzadeh F, Mazaheripour H, Barros JAO, and Sena-Cruz J. Shear capacity of HPFRC beams flexurally reinforced with steel and prestressed GFRP bars. Proceedings of the 11th international symposium on fiber reinforced polymers for reinforced concrete structure (FRPRCS-11), Guimaraes, Portugal, 25-28 June 2013.

[40] Edalat Bahbahani A, Barros JAO, and Ventura-Gouveia A. Plastic-damage smeared crack model to simulate the behaviour of structures made by cement based materials. Journal of Solid and Structures 2015; 73-74: 20-40. http://dx.doi.org/10.1016/j.ijsolstr.2015.07.027.

[41] De Borst R, and Nauta P. Non-orthogonal cracks in a smeared finite elements model. Journal of Engineering Computations, $1985 ; 2: 35-46$.

[42] Ventura-Gouveia A. Constitutive models for the material nonlinear analysis of concrete structures including time dependent effects. Doctoral Thesis: University of Minho, Portugal, 2011.

[43] Barros JAO, Costa IG, Ventura-Gouveia A. CFRP flexural and shear strengthening technique for RC beams: experimental and numerical research. Advances in Structural Engineering Journal 2011; 14(3): 559-581.

[44] Sena-Cruz JM. Strengthening of concrete structures with near-surface modeling CFRP laminate stirrups. Doctoral Thesis: University of Minho, Portugal, 2004.

[45] Minelli F, Conforti A, Cuenca E, and Plizzari G. Are steel fibers able to mitigate or eliminate size effect in shear? Journal of Material and Structures 2013; 47: 459-473. 


\section{Notation}

\begin{tabular}{|c|c|}
\hline$A_{G F R P}$ & cross sectional area of GFRP bar \\
\hline$A_{c}$ & cross section of beam \\
\hline$A_{s}$ & cross sectional area of steel bar \\
\hline$a$ & shear span of the beam \\
\hline$b$ & web width \\
\hline$b_{f}$ & flange width \\
\hline$D_{t}^{c r}$ & stiffness modulus corresponding to the fracture mode II \\
\hline$\underline{D}^{e}$ & linear elastic constitutive matrix \\
\hline$d$ & effective depth of beam \\
\hline$d_{f}$ & steel fiber diameter \\
\hline$d_{G F R P}$ & central distance of GFRP bar from top face of section \\
\hline$d_{a}$ & maximum size of aggregate \\
\hline$\eta_{f}$ & bond efficiency factor \\
\hline$d_{c}$ & scalar damage variable for compression \\
\hline$d_{s}$ & central distance of steel bar from top face of section \\
\hline$d_{s, e q}$ & equivalent steel effective depth \\
\hline$E_{c m}$ & modulus of elasticity of concrete \\
\hline$E_{G F R P}$ & modulus of elasticity of GFRP bars \\
\hline$E_{s}$ & modulus of elasticity of steel bar \\
\hline$F_{f}$ & fiber factor \\
\hline$F_{f, o p t}$ & optimum fiber factor \\
\hline$f$ & yield function \\
\hline$f_{\text {GFRP }}$ & stress in GFRP rebars \\
\hline$f_{G F R P, u}$ & tensile strength of GFRP rebars \\
\hline$f_{\text {Ftuk }}$ & characteristic value of ultimate residual tensile strength of FRC \\
\hline$f_{\text {Ftum }}$ & average value of ultimate residual tensile strength of FRC \\
\hline
\end{tabular}




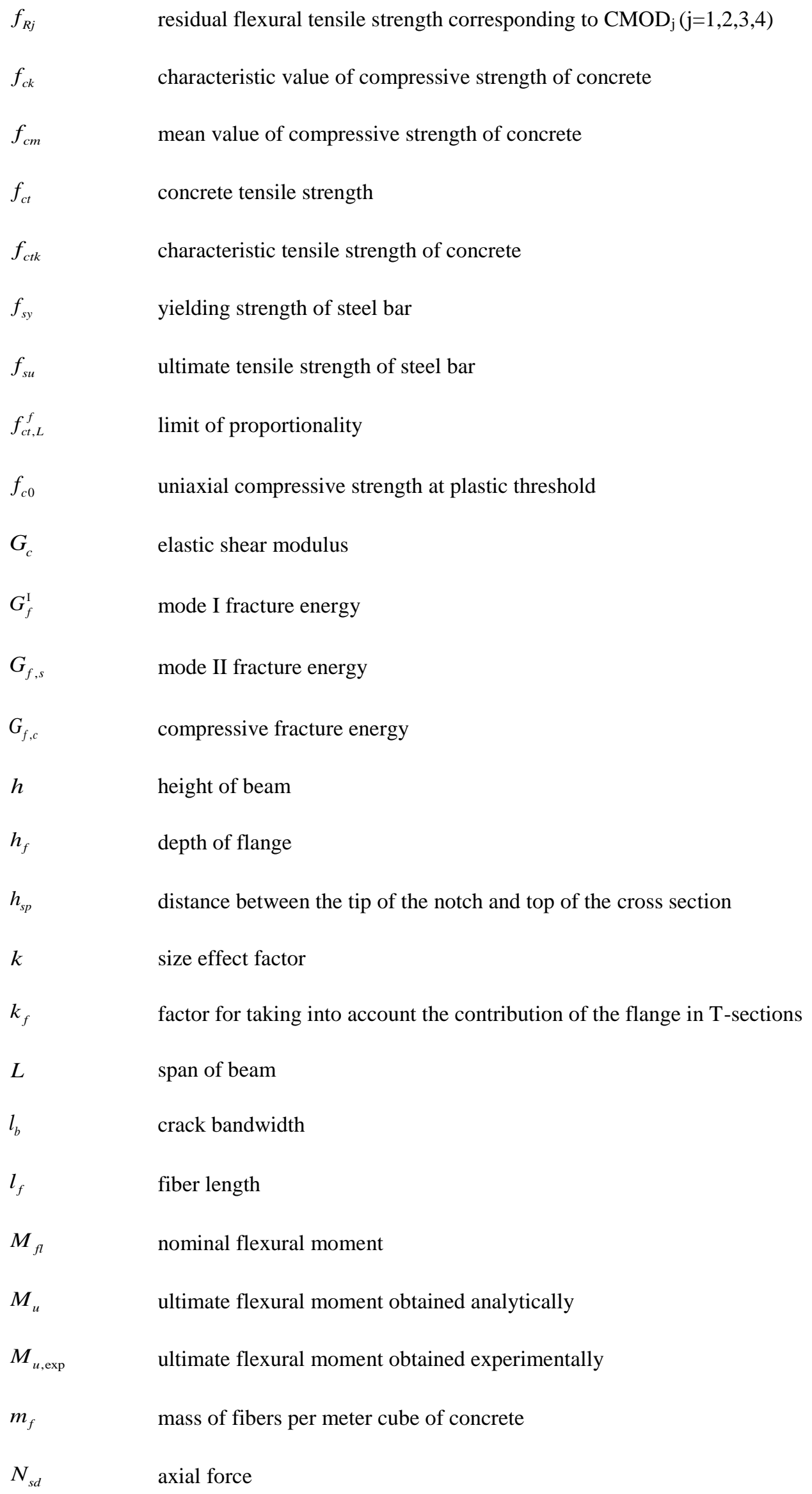




\begin{tabular}{|c|c|}
\hline$P$ & total applied load on beam \\
\hline$P_{1}$ & parameter that defines the amount of the decrease of $\beta$ upon increasing $\varepsilon_{n}^{c r}$ \\
\hline$V_{M C 2010}$ & estimated shear resistance according to the proposed formula by MC2010 \\
\hline$V_{R d, F}$ & design shear resistance attributed to the FRC \\
\hline$V_{\text {RILEM }}$ & estimated shear resistance according to the proposed formula by RILEM TC 162-TDF \\
\hline$V_{\text {anal }}$ & calculated shear resistance of beams \\
\hline$V_{c d}$ & design value of shear resistance attributed to plain concrete \\
\hline$V_{\text {exp }}$ & shear resistance of beams, obtained experimentally \\
\hline$V_{f}$ & fiber volume fraction \\
\hline$V_{f d}$ & design value of shear resistance attributed to steel fibers \\
\hline$V_{\text {Soetens } 2015}$ & estimated shear resistance according to Soetens (2015) formula \\
\hline$V_{u}$ & maximum shear resistance \\
\hline$V_{w d}$ & design value of shear resistance attributed to transversal reinforcement \\
\hline$v_{u}$ & ultimate shear strength \\
\hline$W_{f}$ & width of flange \\
\hline$W_{w}$ & web width \\
\hline$\alpha_{0}$ & $\begin{array}{l}\text { material constant to define the beginning of the nonlinear behavior in uniaxial } \\
\text { compressive stress-strain test }\end{array}$ \\
\hline$\alpha_{i}(i=1,2,3)$ & normalized stress parameter in quadrilinear diagram \\
\hline$\alpha_{\text {red }}$ & fiber reinforcement effectiveness factor \\
\hline$\beta$ & shear retention factor \\
\hline$\xi_{i}(i=1,2,3)$ & normalized strain parameter in quadrilinear diagram \\
\hline$\gamma_{c}$ & partial safety factor for material properties \\
\hline$\gamma_{t}^{c r}$ & shear strain in the crack coordinate system \\
\hline$\gamma_{t, p}^{c r}$ & peak crack shear strain \\
\hline$\gamma_{t, u}^{c r}$ & ultimate crack shear strain \\
\hline$\delta$ & deflection at mid-span of beam \\
\hline
\end{tabular}


hardening parameter in compressive

$\tilde{\epsilon}_{c 1}$

hardening parameter at uniaxial compressive peak stress

$\tilde{\epsilon}_{c u} \quad$ maximum equivalent strain in compression

$\varepsilon_{n}^{c r} \quad$ normal strain in the crack coordinate system

$\varepsilon_{n, u}^{c r} \quad \quad$ ultimate crack normal strain

$\varepsilon_{s y}, \varepsilon_{s h}, \varepsilon_{s u} \quad$ three strain points at the steel constitutive law

$\varepsilon_{c 1} \quad$ strain at uniaxial compression peak stress

$\tau_{t}^{c r} \quad$ shear stress in the crack coordinate system

$\tau_{t, p}^{c r} \quad$ peak crack shear stress

$\Delta \underline{\varepsilon} \quad$ incremental total strain vector

$\Delta \underline{\varepsilon}^{c o} \quad$ incremental concrete strain vector

$\Delta \underline{\varepsilon}^{c r} \quad$ incremental crack strain vector

$\Delta \underline{\varepsilon}^{e} \quad$ incremental elastic strain vector

$\Delta \underline{\varepsilon}^{p} \quad$ incremental plastic strain vector

$\Delta \lambda \quad$ plastic multiplier

$\eta_{f} \quad$ bond efficiency factor

$\theta \quad$ inclination of the compressive strut

$\rho_{\text {eff }} \quad$ effective reinforcement ratio

$\rho_{\text {seq,GFRP }} \quad$ reinforcement ratio of longitudinal GFRP bars converted into an equivalent steel

reinforcement ratio

$\rho_{s} \quad$ reinforcement ratio of longitudinal steel bars

$\rho_{s, e q} \quad$ equivalent steel reinforcement ratio

$\sigma_{f} \quad$ nominal flexural stress

$\sigma_{c p} \quad$ average stress acting on the concrete cross section

$\bar{\sigma}_{c} \quad$ hardening function of the plasticity model

$\underline{\bar{\sigma}} \quad$ stress vector at global coordinate system providing no compressive damage is included 
the stress vector in damaged, respect to compression, configuration

$\bar{\sigma}^{+}$

positive (tensile) part of the stress vector $\underline{\bar{\sigma}}$

$\overline{\bar{\sigma}}^{-}$

negative (compressive) part of the stress vector $\underline{\bar{\sigma}}$

$\sigma_{n}^{c r} \quad$ normal stress in the crack coordinate system

$\sigma_{s y}, \sigma_{s h}, \sigma_{s u} \quad$ three stress points at the steel constitutive law

$\psi$

a function that considers the influences of the aggregate size on flexural capacity

$\omega$

reinforcement factor 


\section{Table captions}

Table 1 - $\quad$ SFRSCC mix composition.

Table 2 - $\quad$ Compressive strength and Youngs modulus of the developted SFRSCC.

Table 3 - $\quad$ Limit of proportionality and residual flexural strength parameters of the developed SFRSCC.

Table 4 - $\quad$ Mechanical properties of GFRP bars.

Table 5 - $\quad$ Mechanical properties of steel bars.

Table 6- Details of the short span beams.

Table 7 - $\quad$ Summary of the test results.

Table 8 - General information about the simulation of the prestress load by means of temperature variation.

Table 9 - $\quad$ Values of the parameters of the steel constitutive model.

Table 10 - Values of the parameters of the constitutive model for concrete.

Table 11 - Shear resistance calculated analytically in comparison with the experimental results.

Table 12 - Shear contribution of concrete and fibers according to the current design codes.

Table B.1 - Data base corresponding to the main characteristics of the beams collected from literature. 


\section{Figure captions}

Fig. 1 - Strain and stress distribution at ultimate condition [23].

Fig. 2 - Combined effect of $a / d_{s, e q}$ and $F_{f}$ on the relative flexural capacity of a beam.

Fig. 3 - Nominal flexural stress vs. CMOD relationship.

Fig. 4 - $\quad$ Beam configuration and test setup (dimensions in $\mathrm{mm}$ ).

Fig. 5 - Relative flexural capacity of beams $v s . a / d_{s, e q}$.

Fig. 6 - Effect of fiber content on both nominal flexural moment, $M_{f l}$, and ultimate moment, $M_{u}$.

Fig. 7 - Load-deflection relationship.

Fig. 8 - $\quad$ Crack pattern of the beams at failure stage.

Fig. 9 - Diagrams for modeling compression [40]: (a) the $\bar{\sigma}_{c}-\tilde{\epsilon}_{c}$ relation used in the plasticity part of the model; (b) the $\left(1-d_{c}\right)-\tilde{\epsilon}_{c}$ relation adopted in isotropic damage law.

Fig. 10 - Diagram for modeling the fracture mode I at the crack coordinate system [42].

Fig. 11 - Diagram for modeling the fracture mode II at the crack coordinate system using: (a) the incremental approach based on a shear retention factor [43]; (b) the shear softening diagram [42].

Fig. 12 - Finite element mesh used for the simulated beams (dimensions in $\mathrm{mm}$ ).

Fig. 13 - Uniaxial constitutive model (for both tension and compression) for the steel bar [44].

Fig. 14 - The numerical prediction of applied load versus the mid-span deflection in compare to the corresponding experimental results of the beam series: (a) Bi-P0; (b) Bi-P20; (c) Bi-P30.

Fig. 15 - The crack patterns predicted by the model for the beam series at the experimental: (a) Bi-P0; (b) Bi-P20; (c) Bi-P30. (In pink color: crack completely open; in red color: crack in the opening process; in cyan color: crack in the reopening process; in green color: crack in the closing process; in blue color: closed crack).

Fig. 16 - Strain in steel reinforcement (obtained at the closest IP to the symmetric axis of the beam) versus the mid-span deflection predicted by the numerical simulations.

Fig. 17 - The predicted load-deformation behavior for all the beam series. 
Fig. 18 - Shear capacity vs. $\sigma_{c p}$ (b) Comparison of the effect of $V_{f d}$ and $V_{c d}$.

Fig. 19 - Contribution of concrete and fiber reinforcement to the calculated ultimate shear capacity of the beams.

Fig. 20 - $\quad V_{\exp } / V_{\text {anal }}$ versus fiber volume fraction for groups of prestressed and non-prestressed RC beams of different beam's cross section.

Fig. 21 - The influence of the beam's cross section depth, $d$, on the $V_{\exp } / V_{\text {anal }}$.

Fig. 22 - Effect of flange factor on safety margin.

Fig. A.1 - The experimental crack pattern for the beam B2-P0 at two stages: at the deflection corresponding to $7.5 \mathrm{~mm}$; at the failure stage. 
Table 1- SFRSCC mix composition.

\begin{tabular}{|c|c|c|c|c|c|c|c|c|}
\hline $\begin{array}{c}\text { Cemen } \\
\mathrm{t}\end{array}$ & Fly ash & $\begin{array}{c}\text { Limeston } \\
\mathrm{e} \\
\text { filler }\end{array}$ & Water & $\begin{array}{c}\text { Super } \\
\text { plasticizer }\end{array}$ & $\begin{array}{c}\text { Fine } \\
\text { sand }\end{array}$ & $\begin{array}{c}\text { River } \\
\text { sand }\end{array}$ & $\begin{array}{c}\text { Coarse } \\
\text { aggregat } \\
\mathrm{e}\end{array}$ & $\begin{array}{c}\text { Steel } \\
\text { fiber }\end{array}$ \\
$\begin{array}{c}\left(\mathrm{kg} / \mathrm{m}^{3}\right. \\
)\end{array}$ & $\begin{array}{c}\mathrm{kgg} / \mathrm{m}) \\
\left(\mathrm{kg} / \mathrm{m}^{3}\right)\end{array}$ & $\begin{array}{c}\left(\mathrm{Liter} / \mathrm{m}^{3}\right. \\
)\end{array}$ & $\left(\mathrm{Liter} / \mathrm{m}^{3}\right)$ & $\begin{array}{c}\left(\mathrm{kg} / \mathrm{m}^{3}\right. \\
)\end{array}$ & $\begin{array}{c}\left(\mathrm{kg} / \mathrm{m}^{3}\right. \\
)\end{array}$ & $\left(\mathrm{kg} / \mathrm{m}^{3}\right)$ & $\begin{array}{c}\left(\mathrm{kg} / \mathrm{m}^{3}\right. \\
)\end{array}$ \\
\hline 462 & 138 & 139 & 208 & 16 & 99 & 697 & 503 & 90 \\
\hline
\end{tabular}


Table 2- Compressive strength and Youngs modulus of the developted SFRSCC.

\begin{tabular}{|c|c|c|c|c|}
\hline \multicolumn{2}{|c|}{ Concrete age (day) } & $f_{c m}{ }^{\mathrm{a}}(\mathrm{MPa})$ & $f_{c k}{ }^{\mathrm{b}}(\mathrm{MPa})$ & $E_{c m}{ }^{\mathrm{c}}(\mathrm{GPa})$ \\
\hline \multirow{2}{*}{3} & Average & 34.08 & 26.08 & 24.39 \\
\cline { 2 - 5 } & CoV & 2.7 & 2.7 & 1.3 \\
\hline \multirow{2}{*}{7} & Average & 52.42 & 44.42 & 31.78 \\
\cline { 2 - 5 } & CoVd & 2.2 & 2.2 & 1.6 \\
\hline \multirow{2}{*}{28} & Average & 64.95 & 56.95 & 34.91 \\
\cline { 2 - 5 } & CoVd & 1.4 & 1.4 & 1.7 \\
\hline
\end{tabular}

a Mean value of compressive strength.

${ }^{\mathrm{b}}$ Characteristic value of compressive strength.

cMean value of Young's modulus.

${ }^{\mathrm{d}}$ Coefficient of variation (for 3 specimens). 
Table 3- Limit of proportionality and residual flexural strength parameters of the developed SFRSCC.

\begin{tabular}{|c|c|c|c|c|c|c|c|}
\hline \multicolumn{2}{|c|}{$\begin{array}{c}\text { Concrete age } \\
\text { (day) }\end{array}$} & \multirow{2}{*}{$\begin{array}{c}f_{c t, L}^{f} \\
(\mathrm{MPa})\end{array}$} & $f_{R 1}(\mathrm{MPa})$ & $f_{R 2}(\mathrm{MPa})$ & $f_{R 3}(\mathrm{MPa})$ & $f_{R 4}(\mathrm{MPa})$ & \multirow[t]{2}{*}{$f_{R 3} / f_{R 1}$} \\
\hline & & & $\mathrm{CMOD}_{1}=0.5 \mathrm{~mm}$ & $\mathrm{CMOD}_{2}=1.5 \mathrm{~mm}$ & CMOD3 $=2.5 \mathrm{~mm}$ & $\mathrm{CMOD}_{4}=3.5 \mathrm{~mm}$ & \\
\hline \multirow{2}{*}{3} & Average & 3.74 & 7.42 & 8.59 & 7.75 & 7.09 & 1.04 \\
\hline & $\mathrm{CoV}$ & 4.9 & 16 & 15.5 & 16.2 & 17.8 & - \\
\hline \multirow{2}{*}{7} & Average & 8.58 & 12.79 & 13.77 & 12.87 & 11.88 & 1.01 \\
\hline & $\mathrm{CoV}$ & 18.9 & 13.4 & 11.2 & 11.9 & 13.7 & - \\
\hline \multirow{2}{*}{28} & Average & 8.69 & 15.18 & 17.17 & 14.82 & 12.82 & 0.98 \\
\hline & $\mathrm{CoV}$ & 18.6 & 6.3 & 7.5 & 0.9 & 13.1 & - \\
\hline
\end{tabular}


Table 4- Mechanical properties of GFRP bars.

\begin{tabular}{|c|c|c|c|}
\hline Diameter & Density & $E_{G F R P}^{\mathrm{a}}$ & $f_{G F R P, u}^{\mathrm{b}}$ \\
\hline $\mathrm{mm}$ & $\mathrm{gr} / \mathrm{cm}^{3}$ & $\mathrm{GPa}$ & $\mathrm{N} / \mathrm{mm}^{2}$ \\
\hline 12 & 2.23 & 56 & 1350 \\
\hline
\end{tabular}


Table 5- Mechanical properties of steel bars.

\begin{tabular}{|c|c|c|c|c|}
\hline Diameter & Density & $f_{s y}{ }^{\mathrm{a}}$ & $E_{s} \mathrm{~b}$ & $f_{s u}{ }^{\mathrm{c}}$ \\
\hline $\mathrm{mm}$ & $\mathrm{gr} / \mathrm{cm}^{3}$ & $\mathrm{~N} / \mathrm{mm}^{2}$ & $\mathrm{GPa}$ & $\mathrm{N} / \mathrm{mm}^{2}$ \\
\hline 10 & 7.85 & 500 & 217 & 594 \\
\hline 12 & 7.85 & 490 & 196 & 591 \\
\hline
\end{tabular}

a $f_{s y}$ Yield tensile stress.

${ }^{\text {b }} E_{s}$ Modulus of elasticity.

c $f_{s u}$ Ultimate tensile strength. 
Table 6- Details of the short span beams.

\begin{tabular}{|c|c|c|c|}
\hline Specimen ID & Prestress level & Prestress & $\begin{array}{c}\text { Effective reinforcing } \\
\text { ratio }\left(\rho_{s, \text { eff }}\right)^{\mathrm{a}} \\
(\%)\end{array}$ \\
\hline B1-P0 & Control & - & 1.2 \\
\hline B2-P0 & Control & - & 1.2 \\
\hline B1-P20 & 20 & 270 & 1.2 \\
\hline B2-P20 & 20 & 270 & 1.2 \\
\hline B1-P30 & 30 & 405 & 1.2 \\
\hline B2-P30 & 30 & 405 & 1.2 \\
\hline
\end{tabular}

${ }^{\text {a }} \rho_{s, \text { eff }}$ Effective reinforcement ratio, see Eq.(10). 
Table 7- Summary of the test results.

\begin{tabular}{|c|c|c|c|c|}
\hline $\begin{array}{c}\text { Specimen } \\
\text { ID }\end{array}$ & $P_{u}{ }^{\mathrm{a}}$ & $\delta_{u}{ }^{\mathrm{b}}$ & $M_{u, \exp }$ & Mod of failure \\
\hline B1-P0 & 303.2 & 12.1 & 79.6 & Shear-flexure \\
\hline B2-P0 & 293.5 & 10.8 & 77.0 & Shear-flexure \\
\hline B1-P20 & 324.5 & 8.1 & 85.2 & Flexure \\
\hline B2-P20 & 322.8 & 8.1 & 84.7 & Shear \\
\hline B1-P30 & 356.1 & 14.8 & 93.5 & Flexure \\
\hline B2-P30 & 353.5 & 14.5 & 92.8 & Flexure \\
\hline
\end{tabular}

a Maximum load,

b deflection corresponding to the maximum load. 
Table 8- General information about the simulation of the prestress load by means of temperature variation.

\begin{tabular}{|l|c|c|c|c|}
\hline & $\begin{array}{l}\text { Prestress } \\
\text { percentage }\end{array}$ & $\begin{array}{l}\text { Stress applied to GFRP } \\
\text { corresponding } \\
\text { prestress level } \\
\sigma_{t}{ }^{a}(\mathrm{MPa})\end{array}$ & $\begin{array}{c}\text { Coefficient of thermal } \\
\text { expansion } \\
\alpha\left(\mathrm{mm} /\left(\mathrm{mm}^{\circ} \mathrm{c}\right)\right)\end{array}$ & $\begin{array}{c}\text { Temperature } \\
\text { variation }\end{array}$ \\
\hline Bi-P0 $(\mathrm{i}=1,2)$ & $0 \%$ & - & - & $\Delta T\left(^{\circ} \mathrm{c}\right)$ \\
\hline Bi-P20 $(\mathrm{i}=1,2)$ & $20 \%$ & 270 & $1 \times 10^{-5}$ & - \\
\hline Bi-P30 $(\mathrm{i}=1,2)$ & $30 \%$ & 405 & $1 \times 10^{-5}$ & -782 \\
\hline
\end{tabular}

${ }^{\mathrm{a}} \sigma_{t}=$ prestress percentage $\times f_{\text {GFRP }, u} ; f_{\text {GFRP }, u}=1350 \mathrm{MPa}$.

Note: the thermal strain and corresponding stress are calculated from: $\varepsilon_{t}=\alpha \Delta T ; \sigma_{t}=E_{\text {GFRP }} \varepsilon_{t}$. 
Table 9- Values of the parameters of the steel constitutive model.

\begin{tabular}{|c|c|c|c|c|c|c|c|}
\hline $\begin{array}{c}\text { Diamet } \\
\text { er } \\
(\mathrm{mm})\end{array}$ & $\varepsilon_{s y}(\%)$ & $\sigma_{s y}\left(N / \mathrm{mm}^{2}\right)$ & $\varepsilon_{s h}(\%)$ & $\sigma_{s h}\left(N / \mathrm{mm}^{2}\right)$ & $\varepsilon_{s u}(\%)$ & $\sigma_{s u}\left(N / m^{2}\right)$ & $\begin{array}{c}\text { Third branch } \\
\text { exponent }\end{array}$ \\
\hline 10,12 & 0.28 & 500 & 0.28 & 500 & 10.0 & 591 & 1 \\
\hline
\end{tabular}


Table 10- Values of the parameters of the constitutive model for concrete.

\begin{tabular}{|l|l|}
\hline Property & Value \\
\hline Poisson's ratio & $v=0.2$ \\
\hline Young's modulus & $E_{c m}=34000 \mathrm{~N} / \mathrm{mm}^{2}$ \\
\hline Compressive strength & $f_{c m}=65 \mathrm{~N} / \mathrm{mm}^{2}$ \\
\hline $\begin{array}{l}\text { Parameter defining the plastic-damage } \\
\text { model }\end{array}$ & $\alpha_{0}=0.4 ; \varepsilon_{c 1}=0.004 ; G_{f, c}=65 \mathrm{~N} / \mathrm{mm}$ \\
\hline $\begin{array}{l}\text { Quadrilinear tension-softening diagram } \\
\text { Parameter defining the mode I fracture } \\
\text { energy available to the new crack [44] }\end{array}$ & $f_{c t}=3.25 \mathrm{~N} / \mathrm{mm}^{2} ; G_{f}^{I}=6.0 \mathrm{~N} / \mathrm{mm} ;$ \\
\hline $\begin{array}{l}\text { Parameters defining the crack shear stress- } \\
\text { crack shear strain softening diagram }\end{array}$ & $\xi_{1}=0.0005 ; \alpha_{1}=0.75 ; \xi_{2}=0.0025 ; \alpha_{2}=1.0 ; \xi_{3}=0.1 ; \alpha_{3}=0.6$ \\
\hline Crack bandwidth & 2 \\
\hline Threshold angle [44] & square root of the area of Gauss integration point \\
\hline $\begin{array}{l}\text { Maximum number of cracks per integration } \\
\text { point [44] }\end{array}$ & 2 \\
\hline
\end{tabular}


Table 11- Shear resistance calculated analytically in comparison with the experimental results.

\begin{tabular}{|c|c|c|c|c|c|c|c|c|}
\hline $\begin{array}{c}\text { Specime } \\
\text { n ID }\end{array}$ & $\begin{array}{l}V_{\text {exp }} \\
(\mathrm{kN})\end{array}$ & $\begin{array}{c}v_{u} \\
(\mathrm{MPa})\end{array}$ & $\begin{array}{c}V_{M C 2010} \\
(\mathrm{kN})\end{array}$ & $\frac{V_{\text {exp }}}{V_{M C 2010}}$ & $\begin{array}{c}V_{\text {RILEM }} \\
(\mathrm{kN})\end{array}$ & $\frac{V_{\text {exp }}}{V_{\text {RILEM }}}$ & $\begin{array}{c}V_{\text {Soetens } 2015} \\
(\mathrm{kN})\end{array}$ & $\frac{V_{\text {exp }}}{V_{\text {Sotens }}}$ \\
\hline B1-P0 & 152.34 & 4.3 & 94.39 & 1.61 & 158.88 & 0.96 & 180.02 & 0.84 \\
\hline B2-P0 & 146.73 & 4.2 & 94.39 & 1.55 & 158.88 & 0.92 & 180.02 & 0.81 \\
\hline B1-P20 & 162.24 & 4.6 & 97.97 & 1.65 & 162.47 & 1.00 & 188.15 & 0.86 \\
\hline B2-P20 & 161.41 & 4.6 & 97.97 & 1.64 & 162.47 & 0.99 & 188.15 & 0.85 \\
\hline B1-P30 & 178.05 & 5.6 & 99.75 & 1.78 & 164.26 & 1.08 & 191.96 & 0.93 \\
\hline B2-P30 & 176.74 & 5.0 & 99.75 & 1.76 & 164.26 & 1.07 & 191.96 & 0.92 \\
\hline Average & & & & 1.66 & & 1.00 & & 0.87 \\
\hline $\mathrm{CoV}$ & & & & 5.33 & & 6.20 & & 5.42 \\
\hline
\end{tabular}


Table 12- Shear contribution of concrete and fibers according to the current design codes.

\begin{tabular}{|c|c|c|c|c|c|c|c|c|c|c|}
\hline \multirow[t]{2}{*}{ Reference } & \multirow{2}{*}{$\begin{array}{c}\text { Beam } \\
\text { ID }\end{array}$} & \multicolumn{2}{|c|}{$V_{M C 2010}$} & \multirow{2}{*}{$\frac{V_{\exp }}{V_{M C 2010}}$} & \multicolumn{2}{|c|}{$V_{\text {RILEM }}$} & \multirow{2}{*}{$\frac{V_{\exp }}{V_{R I L E M}}$} & \multicolumn{2}{|c|}{$V_{\text {Soetens } 2015}$} & \multirow{2}{*}{$\frac{V_{\text {exp }}}{V_{\text {Soetens }}}$} \\
\hline & & $\begin{array}{l}V_{c d} \\
(\%)\end{array}$ & $\begin{array}{l}V_{f d} \\
(\%)\end{array}$ & & $\begin{array}{l}V_{c d} \\
(\%)\end{array}$ & $\begin{array}{l}V_{f d} \\
(\%)\end{array}$ & & $\begin{array}{l}V_{c d} \\
(\%)\end{array}$ & $\begin{array}{l}V_{f d} \\
(\%)\end{array}$ & \\
\hline \multirow{3}{*}{$\begin{array}{l}\text { Cuenca and } \\
\text { Serna [36] }\end{array}$} & Th750-F60-P/1 & 72 & 28 & 1.58 & 61 & 39 & 1.34 & 41 & 59 & 1.12 \\
\hline & Th750-F60-P/2 & 72 & 28 & 1.40 & 61 & 39 & 1.19 & 44 & 56 & 1.06 \\
\hline & Th800-F60-P/3 & 72 & 28 & 1.62 & 61 & 39 & 1.36 & 42 & 58 & 1.15 \\
\hline \multirow{9}{*}{$\begin{array}{l}\text { Minelli et } \\
\text { al. [45] }\end{array}$} & Rh500-F0/4 & 100 & - & 1.00 & 100 & - & 1.00 & 100 & 0 & 1.30 \\
\hline & Rh500-F50/5 & 54 & 46 & 1.19 & 51 & 49 & 1.12 & 33 & 67 & 0.97 \\
\hline & Rh500-F75/6 & 52 & 48 & 1.11 & 46 & 54 & 0.99 & 29 & 71 & 0.84 \\
\hline & Rh1000-F0/7 & 100 & - & 0.88 & 100 & - & 0.88 & 100 & 0 & 1.14 \\
\hline & Rh1000-F50/8 & 54 & 46 & 0.74 & 51 & 49 & 0.69 & 30 & 70 & 0.54 \\
\hline & Rh500-F75/9 & 52 & 48 & 0.90 & 46 & 54 & 0.80 & 26 & 74 & 0.61 \\
\hline & Rh1500-F0/10 & 100 & - & 0.70 & 100 & - & 0.70 & 100 & 0 & 0.91 \\
\hline & Rh1500-F50/11 & 54 & 46 & 0.93 & 50 & 50 & 0.86 & 28 & 72 & 0.64 \\
\hline & Rh1500-F75/12 & 52 & 48 & 1.01 & 46 & 54 & 0.88 & 25 & 75 & 0.64 \\
\hline \multirow{3}{*}{$\begin{array}{l}\text { Soltanzade } \\
\text { h et al. [39] }\end{array}$} & Rh300-F90/13 & 53 & 47 & 1.40 & 32 & 68 & 0.85 & 27 & 73 & 0.74 \\
\hline & Rh300-F90-P/14 & 54 & 46 & 1.60 & 33 & 67 & 0.99 & 28 & 72 & 0.84 \\
\hline & Rh300-F90-P/15 & 55 & 45 & 1.66 & 34 & 66 & 1.05 & 29 & 71 & 0.87 \\
\hline \multirow{5}{*}{$\begin{array}{l}\text { Soltanzade } \\
\text { h et al. [18] }\end{array}$} & Ih500-F90/16 & 52 & 48 & 1.94 & 32 & 105 & 0.88 & 19 & 81 & 0.86 \\
\hline & Ih500-F90/17 & 57 & 43 & 1.80 & 38 & 105 & 0.85 & 21 & 79 & 0.81 \\
\hline & Ih500-F90/18 & 60 & 40 & 1.65 & 45 & 104 & 0.82 & 23 & 77 & 0.77 \\
\hline & Ih500-F90/19 & 60 & 40 & 1.55 & 47 & 106 & 0.80 & 23 & 77 & 0.76 \\
\hline & Ih500-F90/20 & 68 & 32 & 1.44 & 61 & 105 & 0.79 & 25 & 75 & 0.74 \\
\hline Average & & & & 1.31 & & & 0.94 & & & 0.87 \\
\hline $\operatorname{CoV}(\%)$ & & & & 28.6 & & & 20.1 & & & 23.6 \\
\hline
\end{tabular}


Table B.1 - Data base corresponding to the main characteristics of the beams collected from literature.

\begin{tabular}{|c|c|c|c|c|c|c|c|c|c|c|c|c|c|c|}
\hline Reference & $\begin{array}{l}\text { Beam } \\
\text { ID }\end{array}$ & $\begin{array}{l}\text { Cross } \\
\text { section }\end{array}$ & $b$ & $d$ & $L$ & $a / d$ & $\rho$ & $f_{c m}$ & $\begin{array}{l}\text { Fiber } \\
\text { type }\end{array}$ & $l_{f}$ & $l_{f} / d_{f}$ & $m_{f}$ & $\sigma_{c p}$ & $V_{\text {exp }}$ \\
\hline & & & $(\mathrm{mm})$ & $(\mathrm{mm})$ & $(\mathrm{mm})$ & & $(\%)$ & $(\mathrm{MPa})$ & & $(\mathrm{mm})$ & & $\begin{array}{c}\left(\mathrm{kg} / \mathrm{m}^{3}\right. \\
)\end{array}$ & (MP) & $(\mathrm{kN})$ \\
\hline \multirow{3}{*}{$\begin{array}{l}\text { Cuenca and } \\
\text { Serna [36] }\end{array}$} & Th750-F60-P/1 & $\mathrm{T}^{\mathrm{a}}$ & 100 & 689 & 5100 & 3 & 1.83 & 60 & $\mathrm{H}^{\mathrm{b}}$ & 40 & 65 & 60 & 8.23 & 392.44 \\
\hline & Th750-F60-P/2 & $\mathrm{T}$ & 100 & 689 & 5100 & 3 & 1.83 & 60 & $\mathrm{H}$ & 40 & 65 & 60 & 8.23 & 347.17 \\
\hline & Th800-F60-P/3 & $\mathrm{T}$ & 100 & 739 & 5100 & 2.8 & 1.71 & 60 & $\mathrm{H}$ & 40 & 65 & 60 & 8.23 & 420.03 \\
\hline \multirow{9}{*}{$\begin{array}{l}\text { Minelli et } \\
\text { al. [45] }\end{array}$} & Rh500-F0/4 & $\mathrm{R}$ & 250 & 440 & 3000 & 3 & 1.12 & 38.7 & $\mathrm{H}$ & 50 & 62.5 & 0 & 0 & 116 \\
\hline & Rh500-F50/5 & $\mathrm{R}$ & 250 & 440 & 5900 & 3 & 1.12 & 32.1 & $\mathrm{H}$ & 50 & 62.5 & 50 & 0 & 240 \\
\hline & Rh500-F75/6 & $\mathrm{R}$ & 250 & 440 & 9000 & 3 & 1.12 & 33.1 & $\mathrm{H}$ & 50 & 62.5 & 75 & 0 & 235 \\
\hline & Rh1000-F0/7 & $\mathrm{R}$ & 250 & 940 & 3000 & 3 & 1.07 & 38.7 & $\mathrm{H}$ & 50 & 62.5 & 0 & 0 & 188 \\
\hline & Rh1000-F50/8 & $\mathrm{R}$ & 250 & 940 & 5900 & 3 & 1.07 & 32.1 & $\mathrm{H}$ & 50 & 62.5 & 50 & 0 & 272 \\
\hline & Rh1000-F75/9 & $\mathrm{R}$ & 250 & 940 & 9000 & 3 & 1.07 & 33.1 & $\mathrm{H}$ & 50 & 62.5 & 75 & 0 & 351 \\
\hline & Rh1000-F0/10 & $\mathrm{R}$ & 250 & 1440 & 3000 & 3 & 1.01 & 38.7 & $\mathrm{H}$ & 50 & 62.5 & 0 & 0 & 211 \\
\hline & $\begin{array}{l}\text { Rh1000- } \\
\text { F50/11 }\end{array}$ & $\mathrm{R}$ & 250 & 1440 & 5900 & 3 & 1.01 & 32.1 & $\mathrm{H}$ & 50 & 62.5 & 50 & 0 & 484 \\
\hline & $\begin{array}{l}\text { Rh1000- } \\
\text { F75/12 }\end{array}$ & $\mathrm{R}$ & 250 & 1440 & 9000 & 3 & 1.01 & 33.1 & $\mathrm{H}$ & 50 & 62.5 & 75 & 0 & 554 \\
\hline \multirow{3}{*}{$\begin{array}{l}\text { Soltanzade } \\
\text { h et al. [39] }\end{array}$} & Rh300-F90/13 & $\mathrm{R}^{\mathrm{c}}$ & 150 & 228.93 & 1210 & 2.2 & 1 & 64.9 & $\mathrm{H}$ & 33 & 65 & 90 & 0 & 133.5 \\
\hline & $\begin{array}{l}\text { Rh300-F90- } \\
\text { P/14 }\end{array}$ & $\mathrm{R}$ & 150 & 228.93 & 1210 & 2.2 & 1 & 64.9 & $\mathrm{H}$ & 33 & 65 & 90 & 0.68 & 159.1 \\
\hline & $\begin{array}{l}\text { Rh300-F90- } \\
\text { P/15 }\end{array}$ & $\mathrm{R}$ & 150 & 228.93 & 1210 & 2.2 & 1 & 64.9 & $\mathrm{H}$ & 33 & 65 & 90 & 1.00 & 169.3 \\
\hline \multirow{5}{*}{$\begin{array}{l}\text { Soltanzade } \\
\text { h et al. [18] }\end{array}$} & Ih500-F90/16 & $\mathrm{I}^{\mathrm{d}}$ & 70 & 419 & 3700 & 3.5 & 0.7 & 67 & $\mathrm{H}$ & 33 & 65 & 90 & 0 & 120.06 \\
\hline & $\begin{array}{l}\text { Ih500-F90- } \\
\text { P/17 }\end{array}$ & I & 70 & 419 & 3700 & 3.5 & 0.7 & 67 & $\mathrm{H}$ & 33 & 65 & 90 & 1.43 & 122.4 \\
\hline & $\begin{array}{l}\text { Ih500-F90- } \\
\text { P/18 }\end{array}$ & I & 70 & 419 & 3700 & 3.5 & 0.7 & 67 & $\mathrm{H}$ & 33 & 65 & 90 & 2.86 & 122.8 \\
\hline & $\begin{array}{l}\text { Ih500-F90- } \\
\text { P/19 }\end{array}$ & I & 70 & 426.14 & 3700 & 3.5 & 0.81 & 67 & $\mathrm{H}$ & 33 & 65 & 90 & 2.86 & 121.24 \\
\hline & $\begin{array}{l}\text { Ih500-F90- } \\
\text { P/20 }\end{array}$ & I & 70 & 419 & 3700 & 3.9 & 0.7 & 67 & $\mathrm{H}$ & 33 & 65 & 90 & 6.61 & 131.1 \\
\hline
\end{tabular}

a T-shape cross section.

b Hooked end steel fiber.

c Rectangular cross section.

d I-shape cross section. 


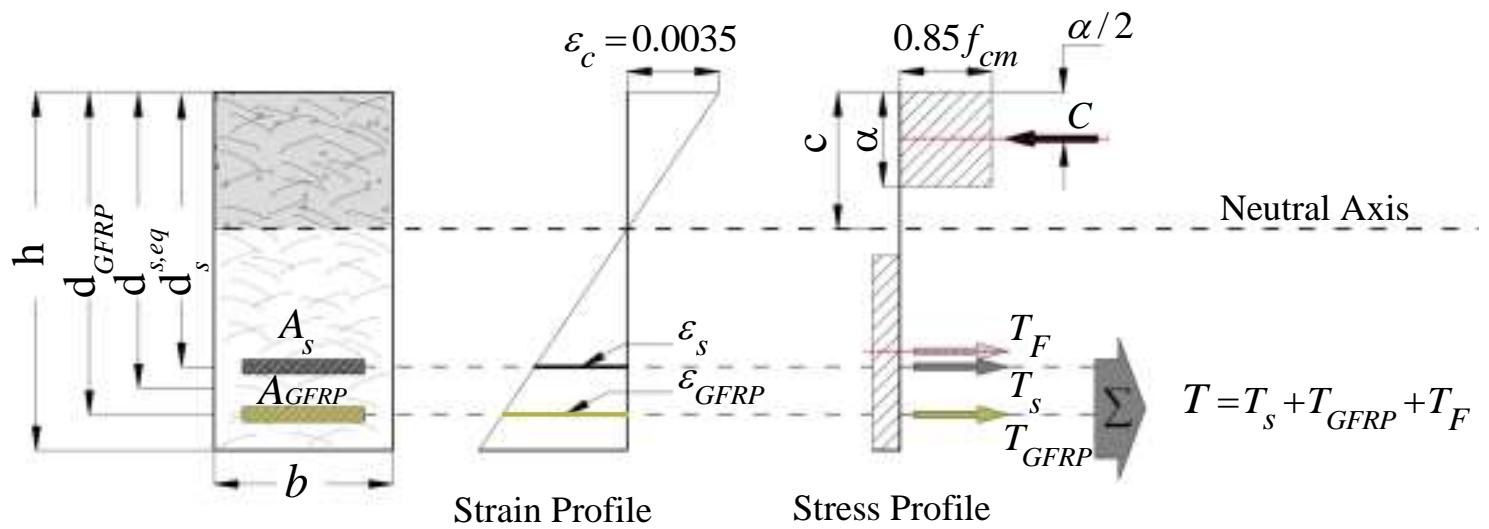

*TF: steel fibers tensile stress,

**Ts: tensile stress in steel reinforcements,

***TGFRP: tensile stress in GFRP rebars,

$* * * * \mathrm{C}$ : compressiv stress in concrete.

Fig. 1- Strain and stress distribution at ultimate condition [23]. 


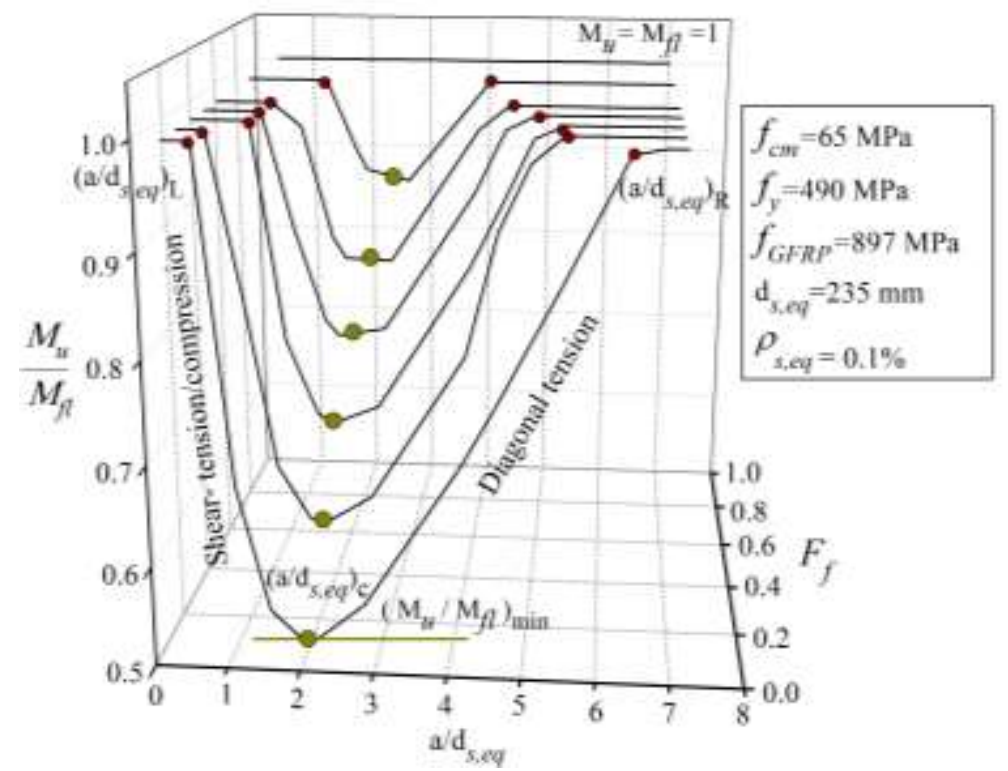

Fig. 2- Combined effect of $a / d_{s, e q}$ and $F_{f}$ on the relative flexural capacity of a beam. 


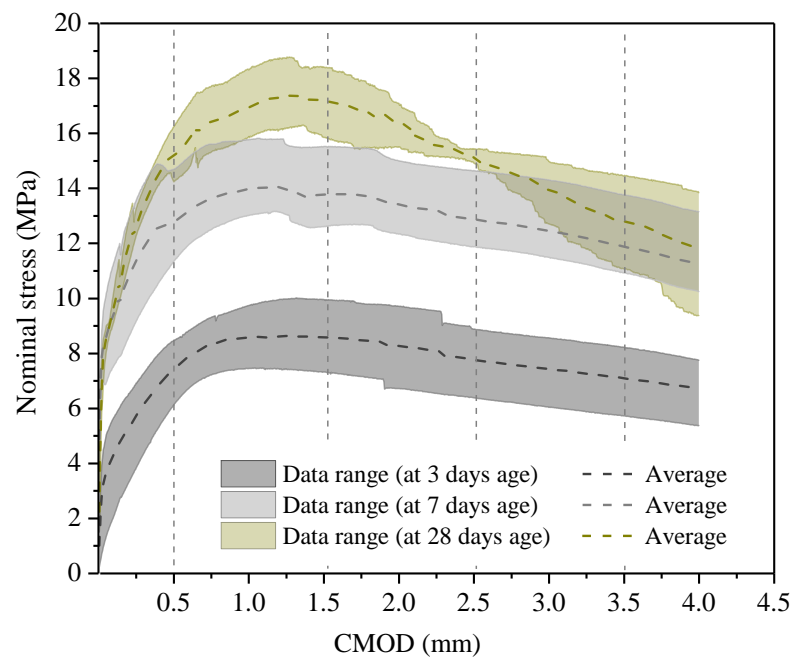

Fig. 3 - Nominal flexural stress vs. CMOD relationship. 

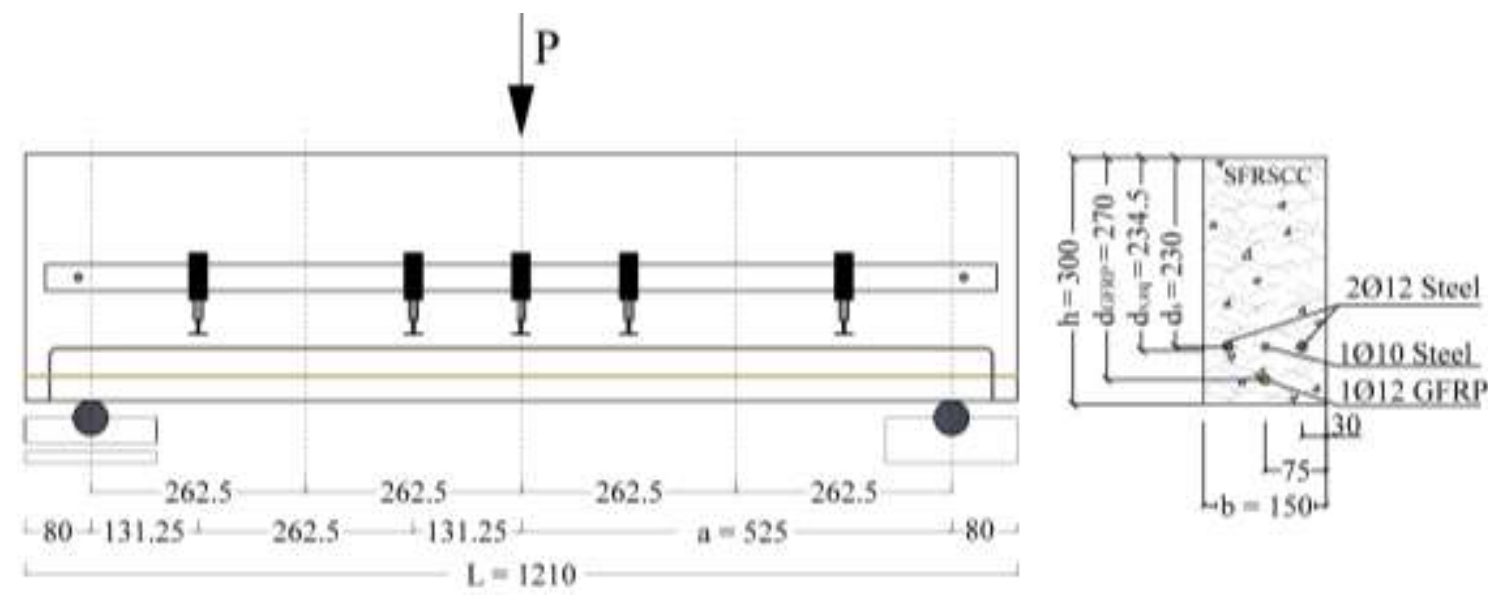

Fig. 4 - Beam configuration and test setup (dimensions in $\mathrm{mm}$ ). 


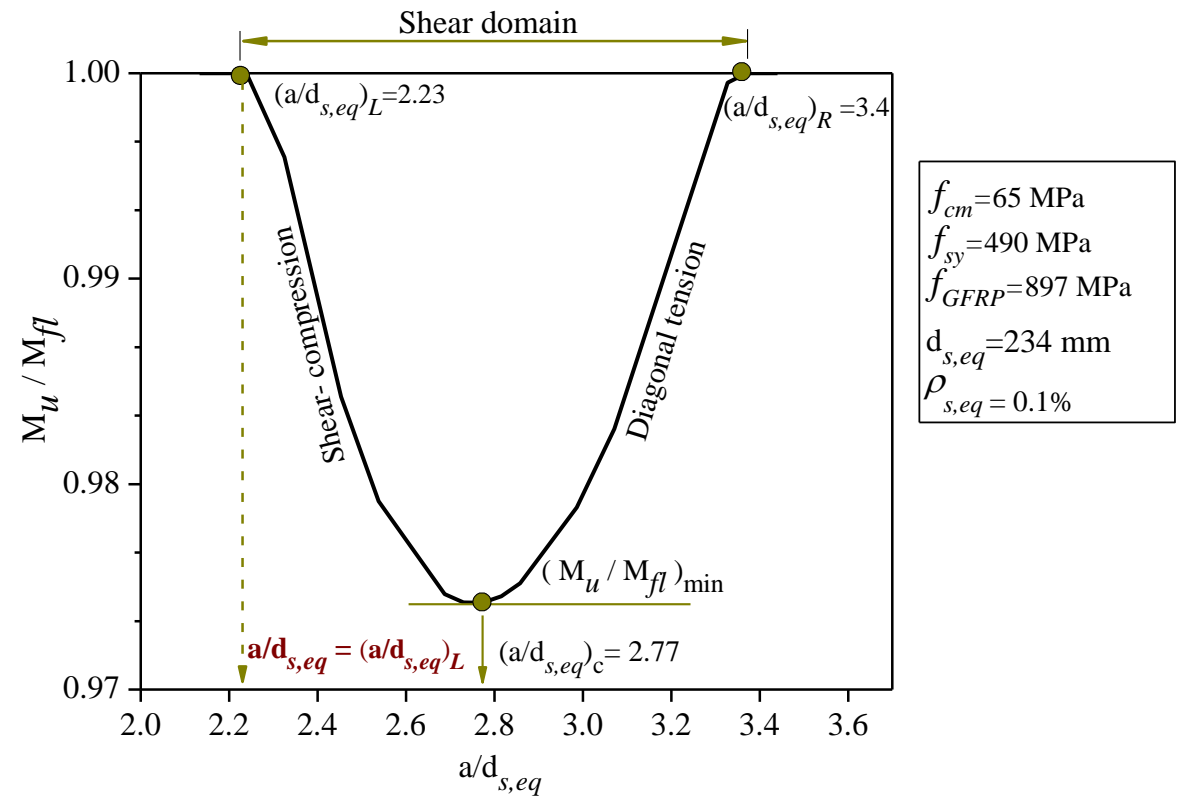

Fig. 5 - Relative flexural capacity of beams $v s . a / d_{s, e q}$. 


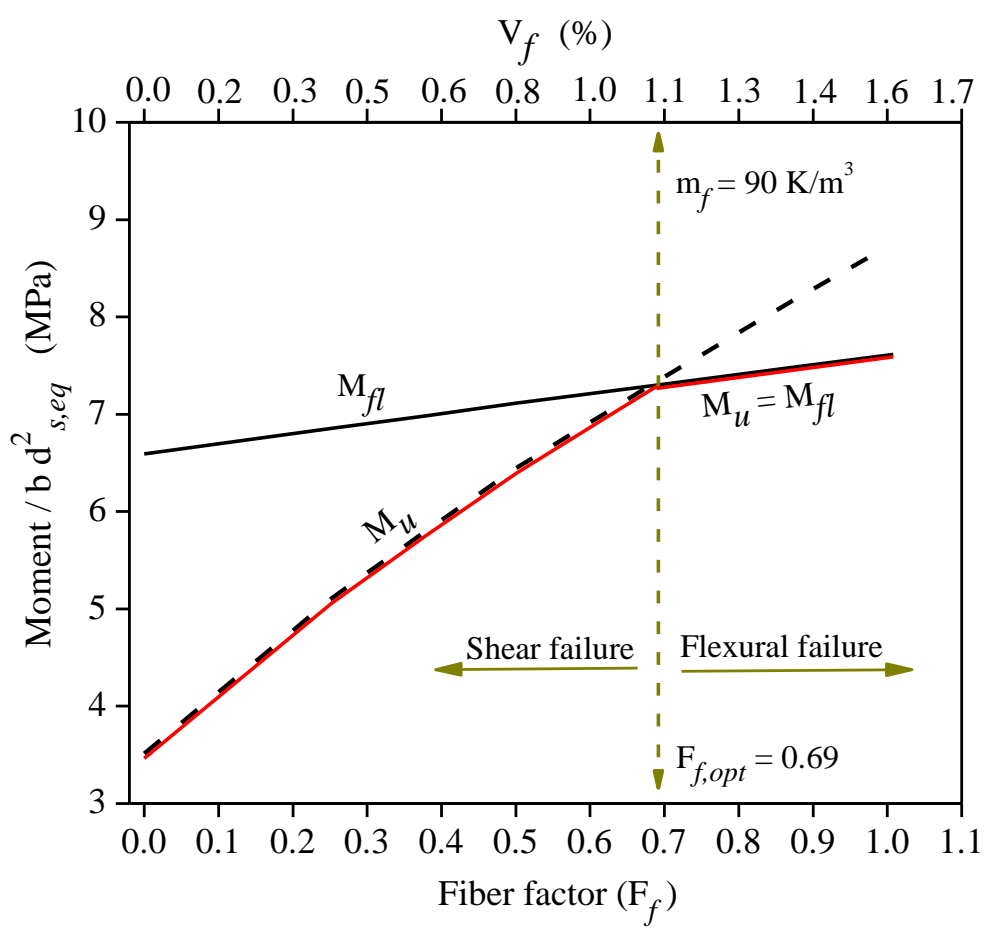

Fig. 6 - Effect of fiber content on both nominal flexural moment, $M_{f l}$, and ultimate moment, $M_{u}$. 


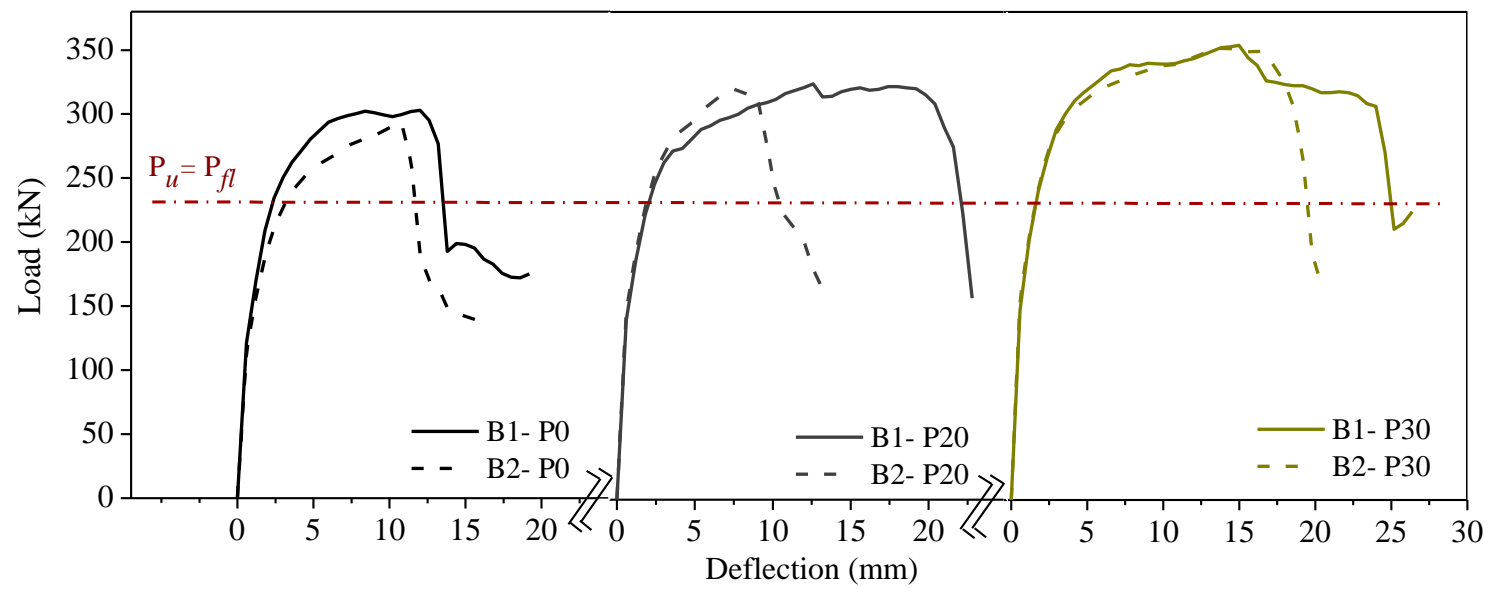

Fig. 7 - Load-deflection relationship. 


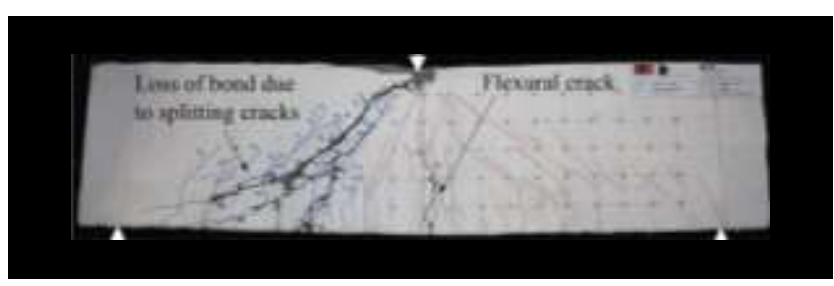

B1-P0

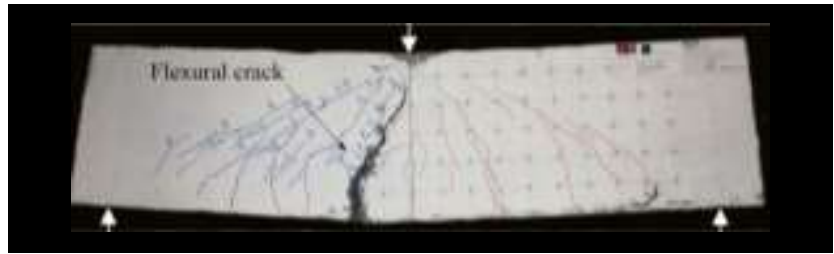

B1-P20

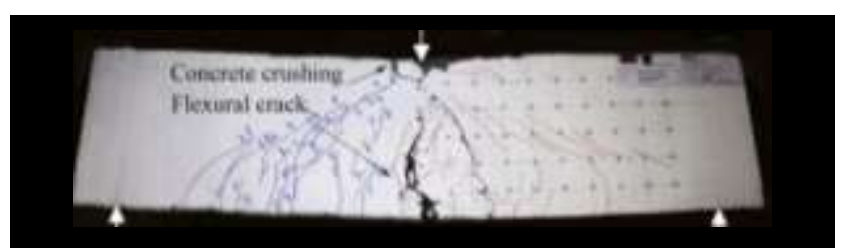

B1-P30

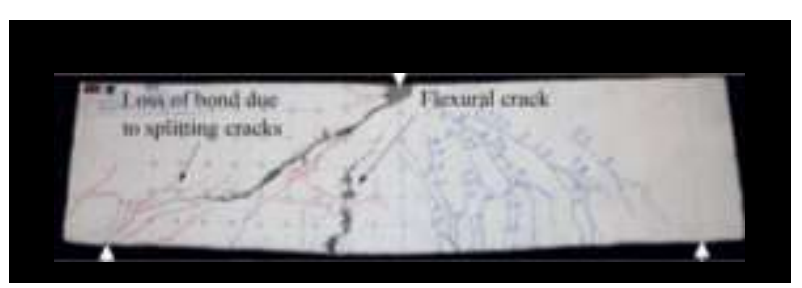

B2-P0

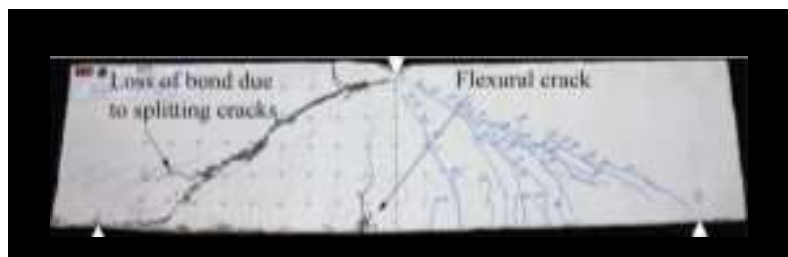

B2-P20

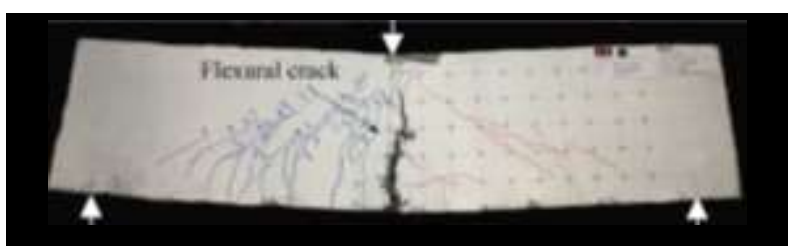

B2-P30

Fig. 8 - Crack pattern of the beams at failure stage. 


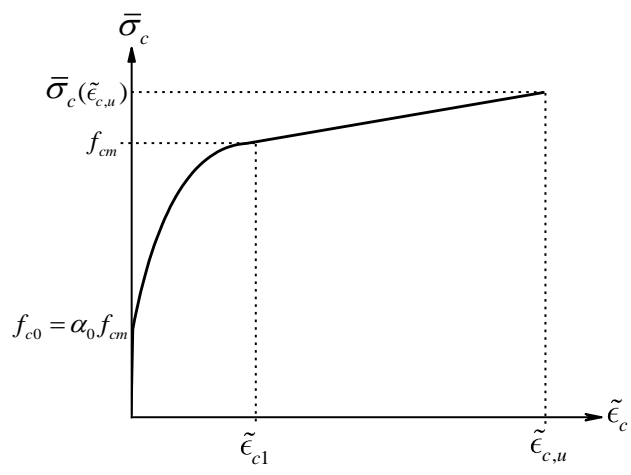

(a)

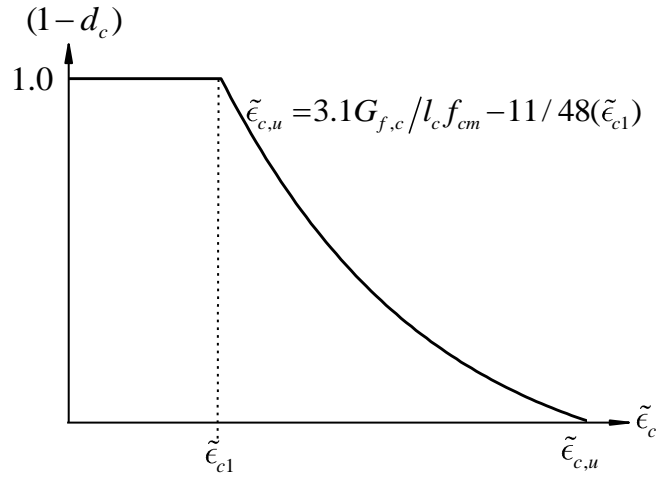

(b)

Fig. 9 - Diagrams for modeling compression [40]: (a) the $\bar{\sigma}_{c}-\tilde{\epsilon}_{c}$ relation used in the plasticity part of the model; (b) the $\left(1-d_{c}\right)-\tilde{\epsilon}_{c}$ relation adopted in isotropic damage law. 


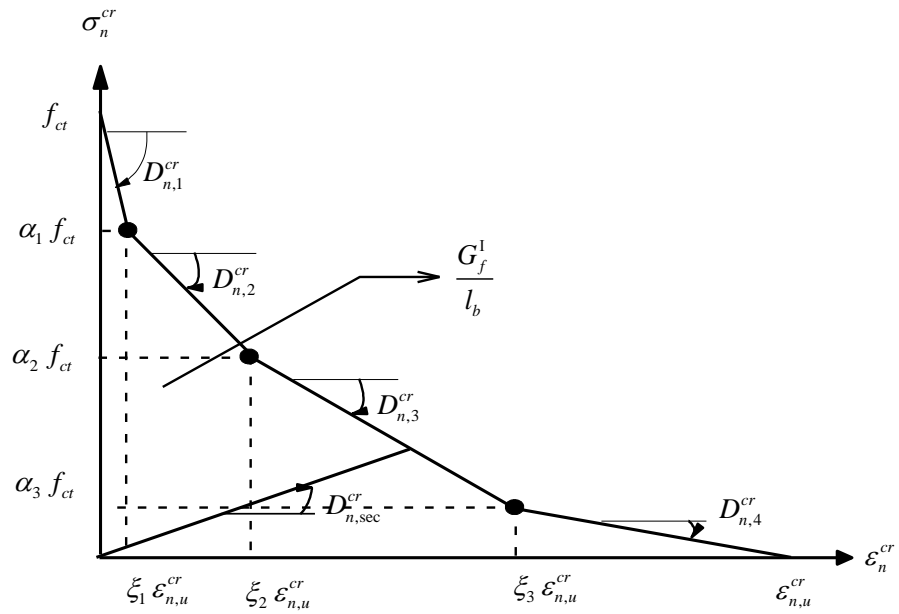

Fig. 10 - Diagram for modeling the fracture mode I at the crack coordinate system [42]. 


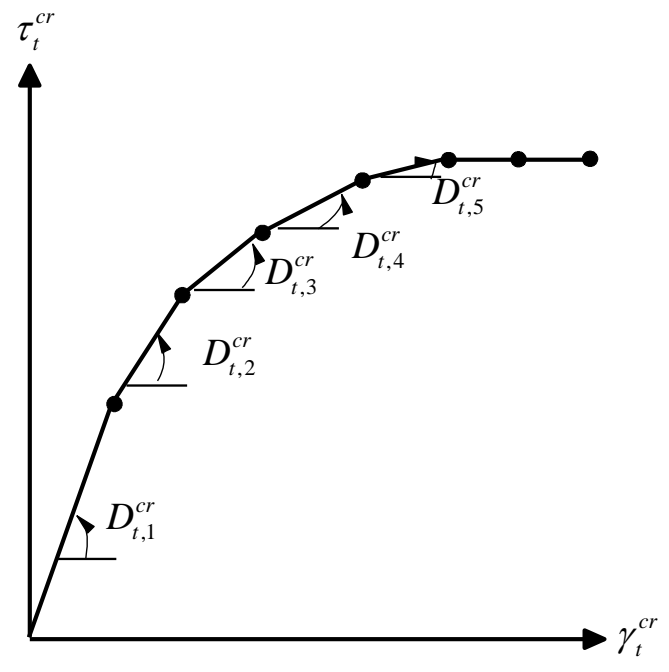

(a)

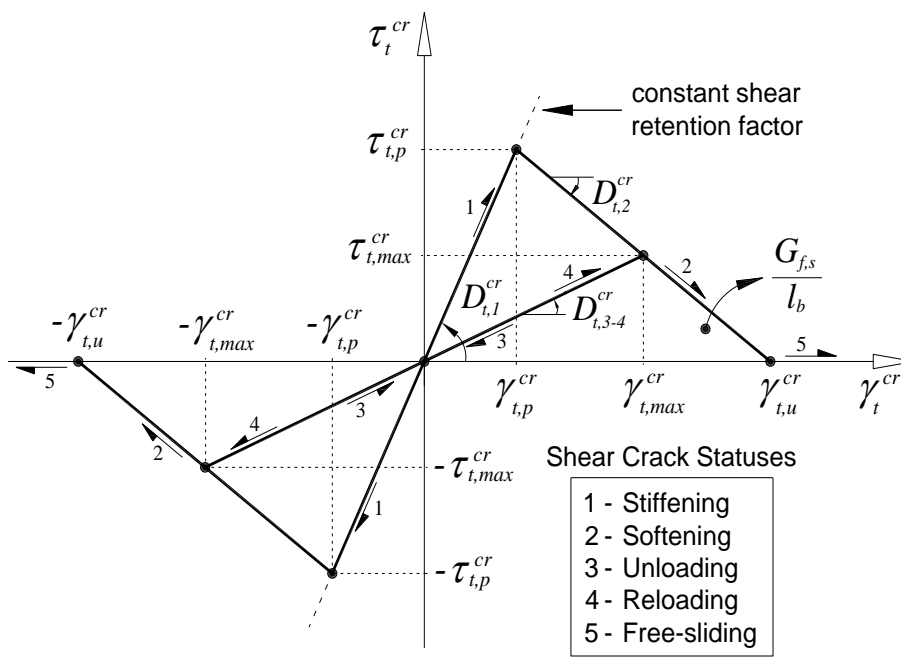

(b)

Fig. 11 - Diagram for modeling the fracture mode II at the crack coordinate system using: (a) the incremental approach based on a shear retention factor [43]; (b) the shear softening diagram [42]. 


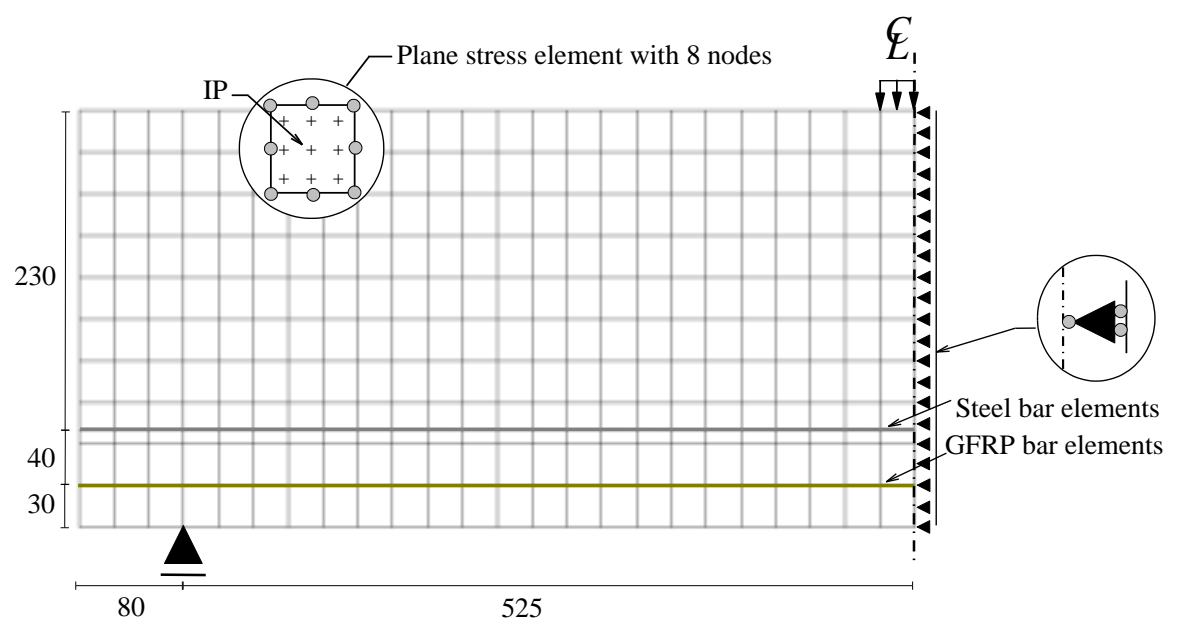

Fig. 12 - Finite element mesh used for the simulated beams (dimensions in mm). 


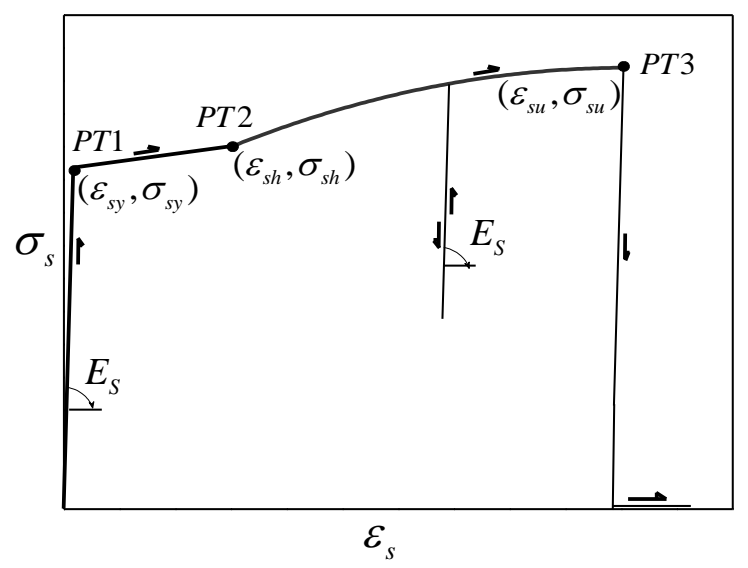

Fig. 13 - Uniaxial constitutive model (for both tension and compression) for the steel bar [44]. 


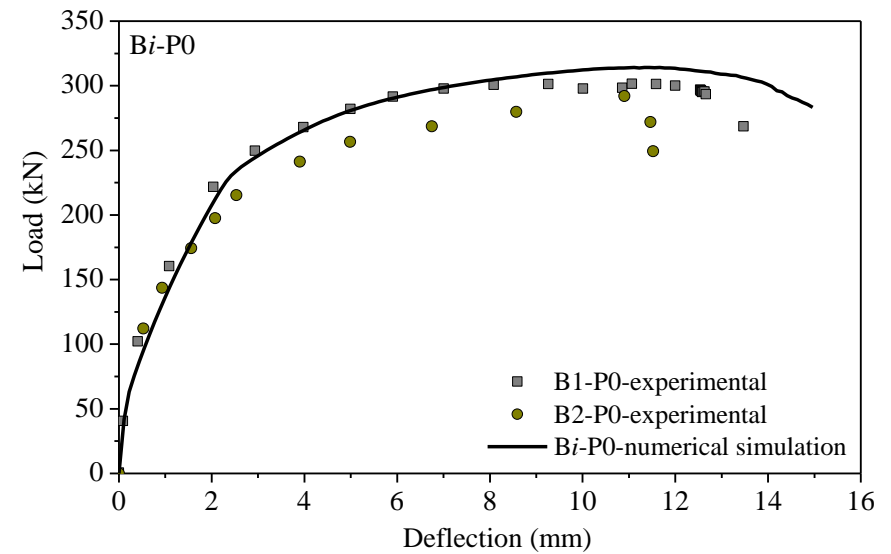

(a)

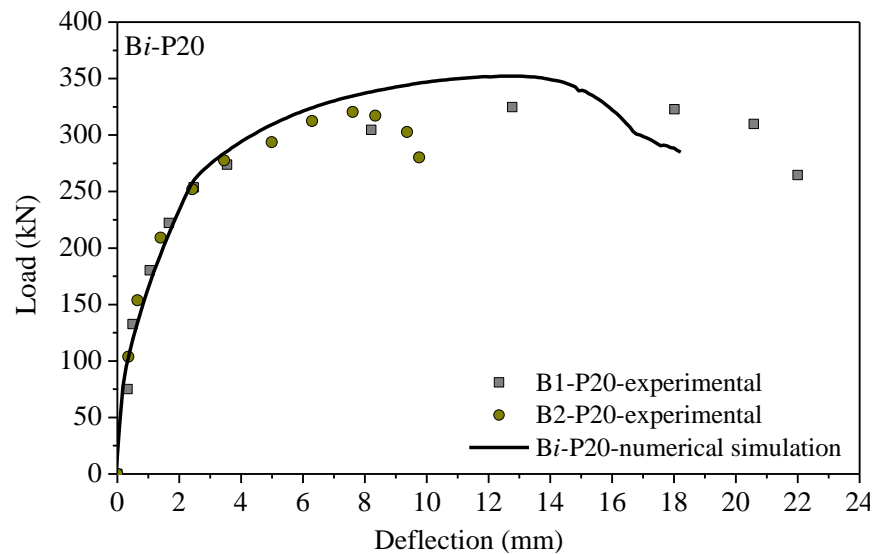

(b)

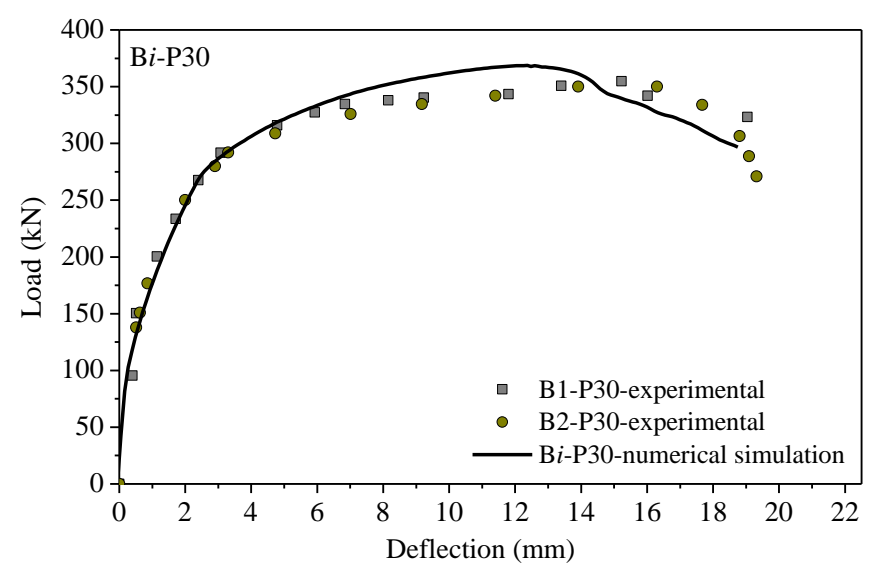

(c)

Fig. 14 - The numerical prediction of applied load versus the mid-span deflection in compare to the corresponding experimental results of the beam series: (a) Bi-P0; (b) Bi-P20; (c) Bi-P30. 

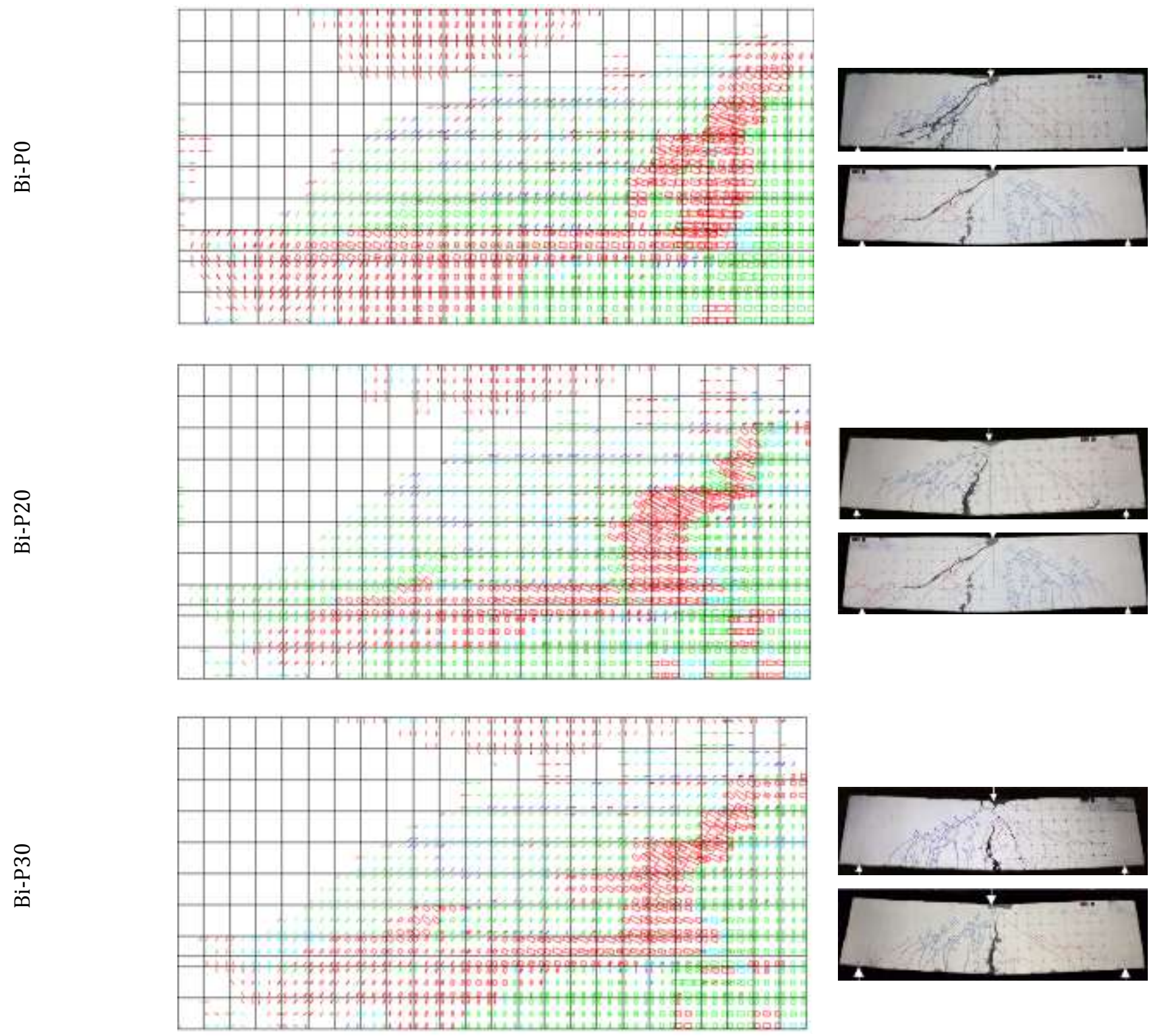

Fig. 15 - The crack patterns predicted by the model for the beam series at the experimental: (a) Bi-P0; (b) Bi-P20; (c) Bi-P30. (In pink color: crack completely open; in red color: crack in the opening process; in cyan color: crack in the reopening process; in green color: crack in the closing process; in blue color: closed crack). 


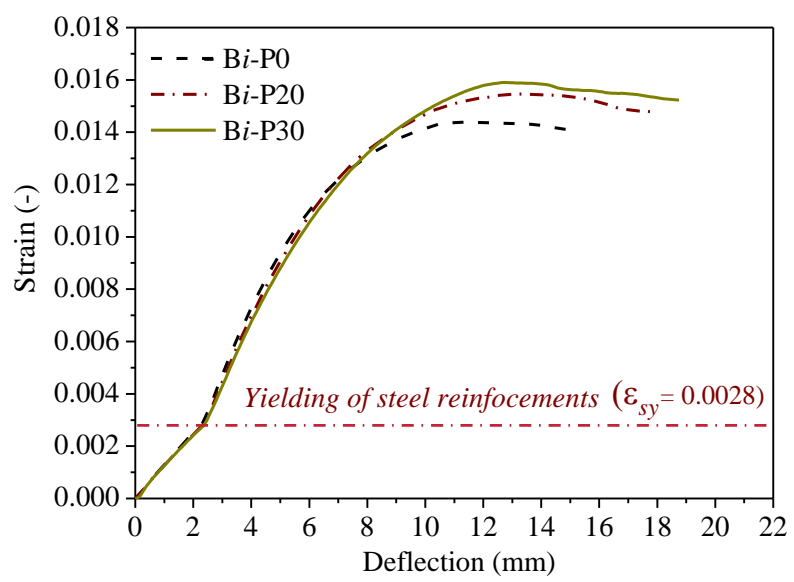

Fig. 16 - Strain in steel reinforcement (obtained at the closest IP to the symmetric axis of the beam) versus the mid-span deflection predicted by the numerical simulations. 


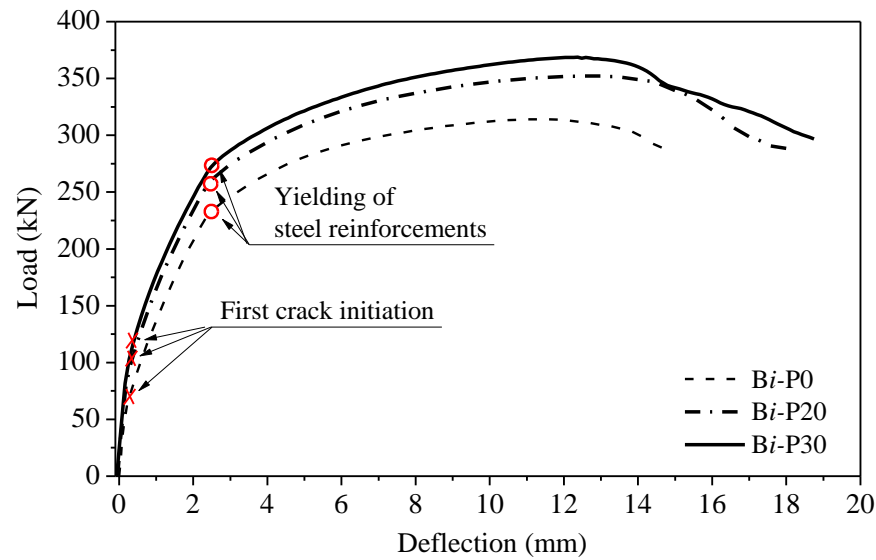

Fig. 17 - The predicted load-deformation behavior for all the beam series. 

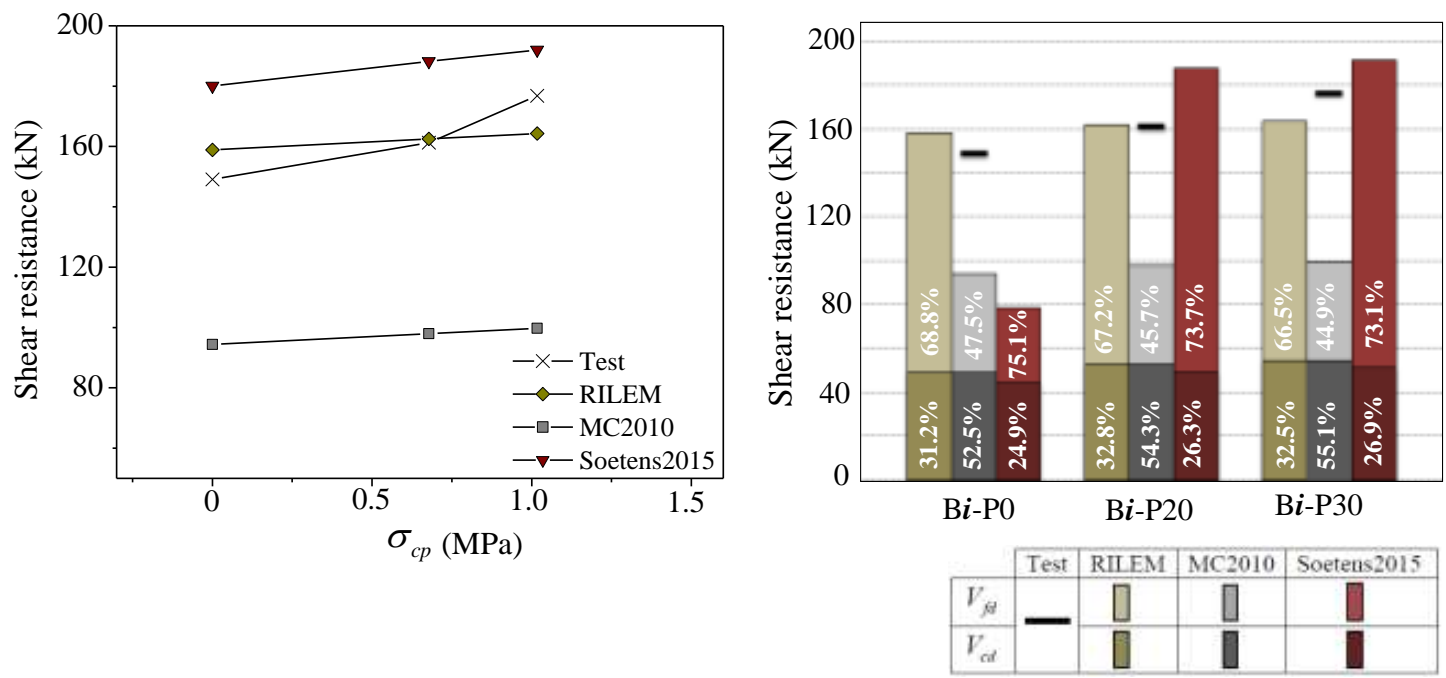

Fig.18 - (a) Shear capacity vs. $\sigma_{c p}$ (b) Comparison of the effect of $V_{f d}$ and $V_{c d}$. 


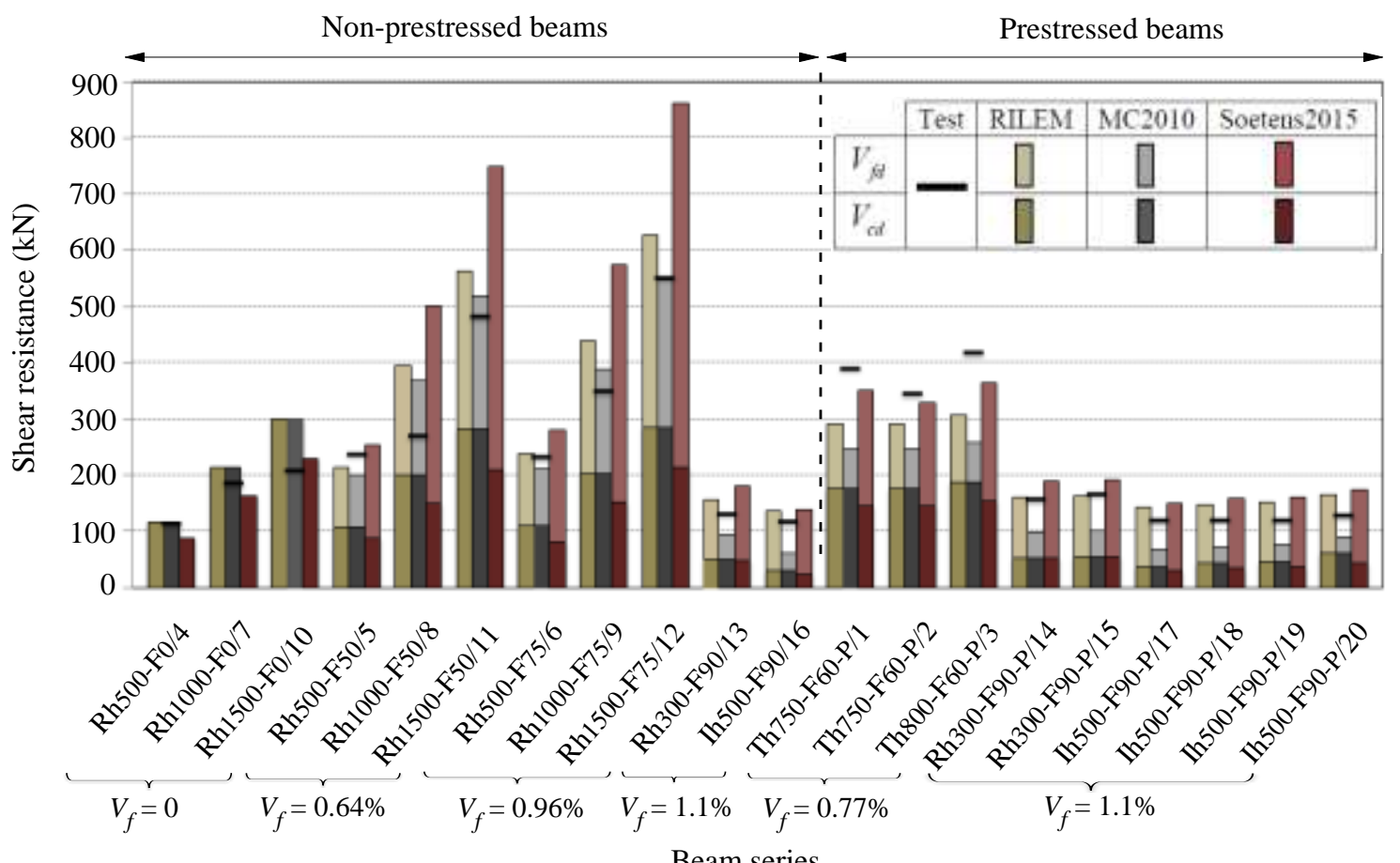

Fig.19 - Contribution of concrete and fiber reinforcement to the calculated ultimate shear capacity of the beams. 


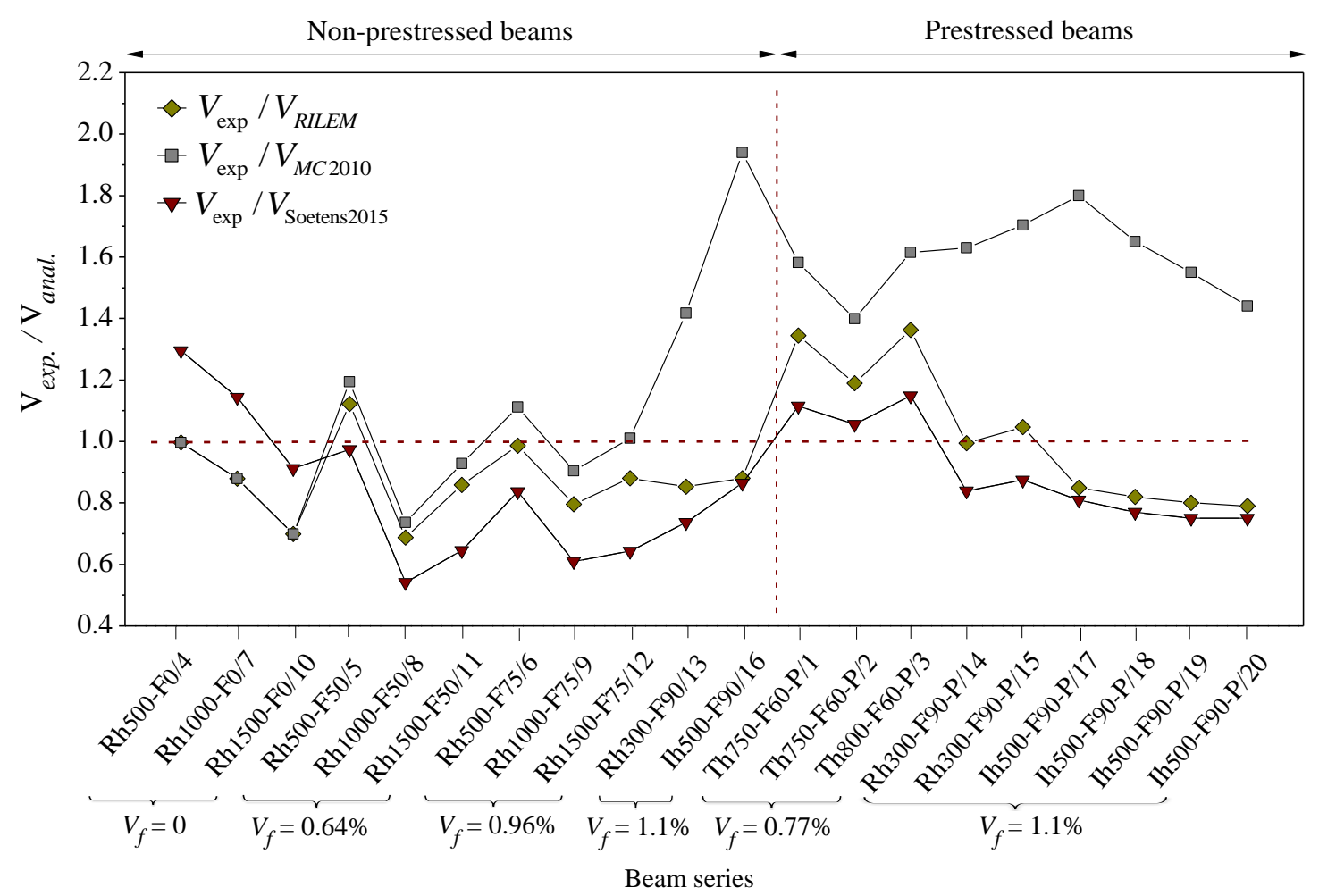

Fig. $20-V_{\text {exp }} / V_{\text {anal }}$ versus fiber volume fraction for groups of prestressed and non-prestressed RC beams of different beam's cross section. 


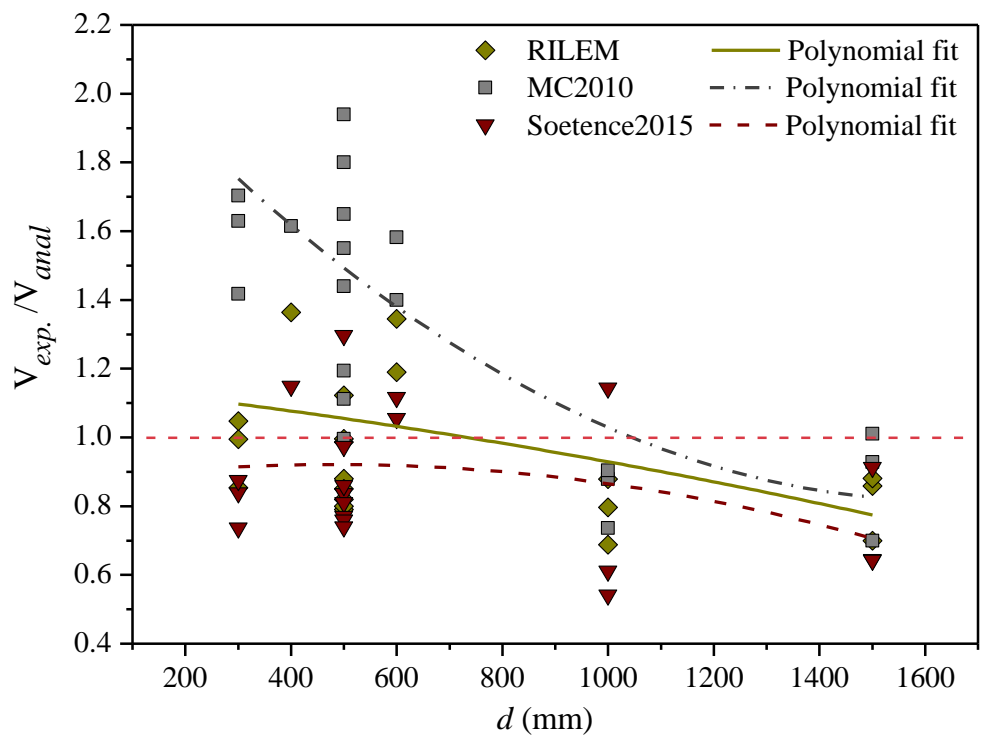

Fig. 21 - The influence of the beam's cross section depth, $d$, on the $V_{\text {exp }} / V_{\text {anal }}$. 


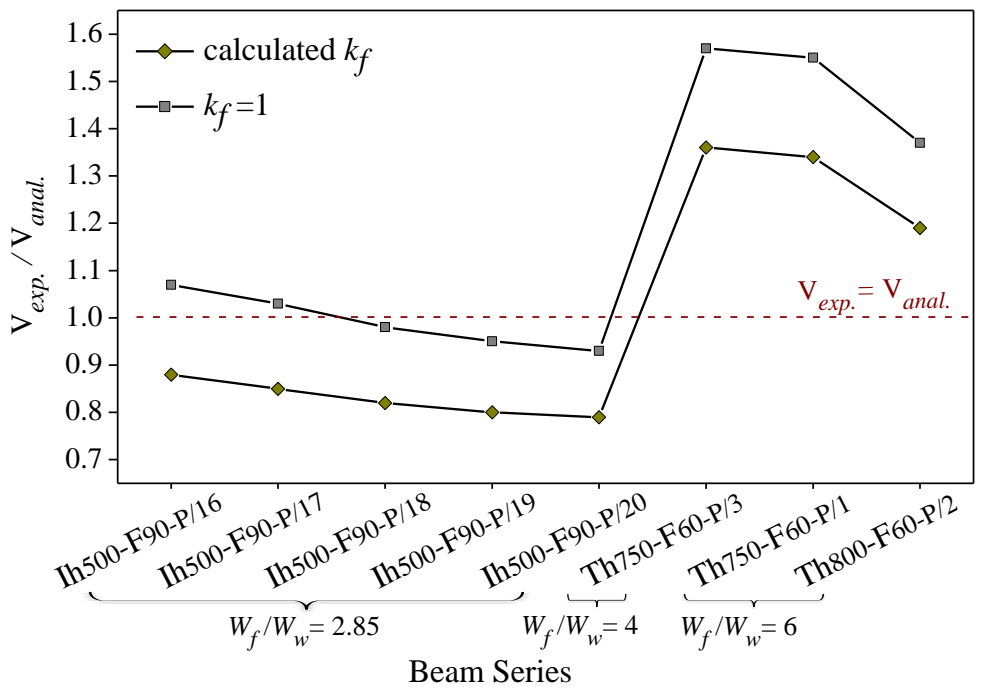

Fig. 22 - Effect of flange factor on safety margin. 


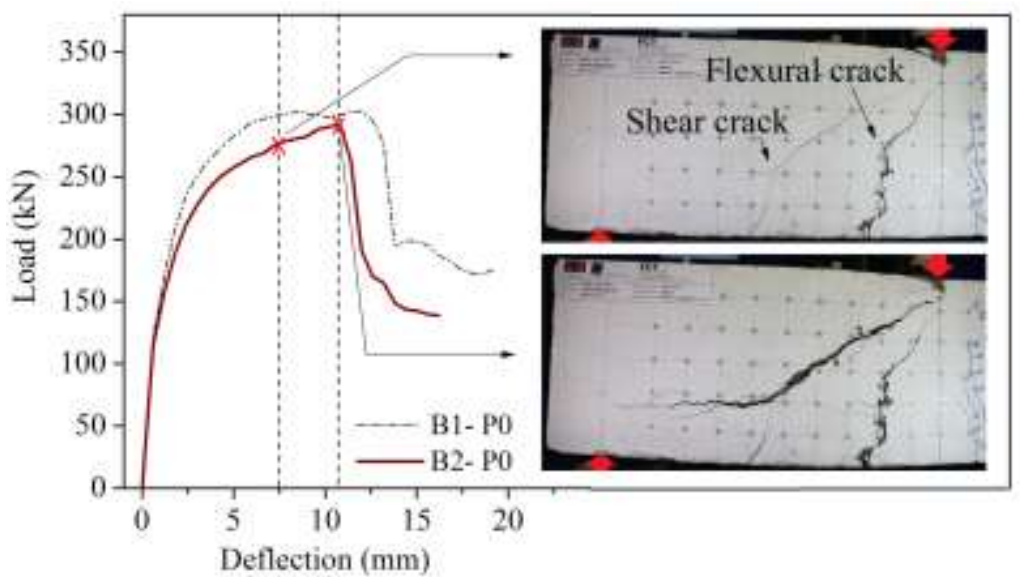

Fig. A.1 - The experimental crack pattern for the beam B2-P0 at two stages: at the deflection corresponding to $7.5 \mathrm{~mm}$; at the failure stage. 